Technology Development ANL/TD/TM01-24

Division

Technology Development Division

Technology Development Division

Technology Development Division

Technology Development Representativity of Fuel and Cladding Division

Technology Development Material Irradiations Using Division

Technology Development a Spallation Neutron Source

Technology Development

Division

Technology Development Division

Technology Development Division

Technology Development Division

Technology Development Division

Technology Development Division

Technology Development Division

Technology Development

Division

Technology Development

Division

Technology Development

Division

Technology Development

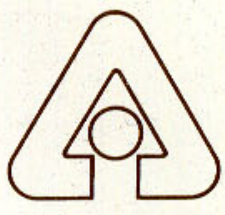

Division

Technology Development

Division

Technology Development

Division

Technology Development

Division

Technology Development

Division 
Argonne National Laboratory, with facilities in the states of Illinois and Idaho, is owned by the United States Government and operated by The University of Chicago under the provisions of a contract with the Department of Energy.

\begin{abstract}
This report was prepared as an account of work sponsored by an agency of the United States Government. Neither the United States Government nor any agency thereof, nor The University of Chicago, nor any of their employees or officers, makes any warranty, express or implied, or assumes any legal liability or responsibility for the accuracy, completeness, or usefulness of any information, apparatus, product, or process disclosed, or represents that its use would not infringe privately owned rights. Reference herein to any specific commercial product, process, or service by trade name, trademark, manufacturer, or otherwise, does not necessarily constitute or imply its endorsement, recommendation, or favoring by the United States Government or any agency thereof. The views and opinions of document authors expressed herein do not necessarily state or reflect those of the United States Government or any agency thereof, Argonne National Laboratory, or The University of Chicago.
\end{abstract}

Available electronically at http://www.doe.gov/bridge

Available for a processing fee to U.S. Department of Energy and its contractors, in paper, from:

U.S. Department of Energy

Office of Scientific and Technical Information

P.O. Box 62

Oak Ridge, TN 37831-0062

phone: (865) 576-8401

fax: (865) 576-5728

email: reports@adonis.osti.gov 


\title{
Representativity of fuel and cladding material irradiations using a spallation neutron source
}

\author{
D. G. Naberejnev and M. Salvatores
}

\begin{abstract}
The present note documents an investigation aimed at understanding phenomena related to the representativity of an irradiation using an intense spallation source, with regards to neutron damage and Helium production.

Two different designs of a spallation neutron source are considered. The first is an intense spallation neutron source (power $\sim 40 \mathrm{MW}$ in the proton beam) proposed at CEA, France as a potential irradiation tool. The second is one of the current models for the TMT (Target for Material Testing) of the ADTF (Accelerator Driven Test Facility) program (power $\sim 8 \mathrm{MW}$ in the proton beam).

For both cases we evaluate neutron flux levels, damage rates due to protons and neutrons, and Helium production both by protons and neutrons.
\end{abstract}




\section{Content}

1 INTRODUCTION

2 CALCULATION METHODS 3

3 INTENSE SPALLATION NEUTRON SOURCE 3

3.1 GEOMETRY AND COMPOSITION 4

3.2 ISNS PHYSICS CHARACTERISTICS 5

3.2 .1 NEUTRON FLUXES

NEUTRON SPECTRUM

ENERGY DEPOSITION

DAMAGE AND HELIUM PRODUCTION IN THE WINDOW

3.2 .3

3.2 .4

3.3 IRRADIATION OF NATURAL IRON SAMPLE IN THE ISNS

3.3.1 NEUTRON AND PROTON INDUCED DAMAGE IN THE IRRADIATION ZONE

3.3.2 HELIUM PRODUCTION IN THE IRRADIATION ZONE

3.4 CONCLUSION

4.1 GEOMETRY

4.2 NEUTRON FLUXES AND SPECTRUM

4.3 IRRADIATION OF IRON IN THE TMT

4.3.1 NEUTRON AND PROTON INDUCED DAMAGE AT IRRADIATION POSITIONS

4.3.2 HELIUM PRODUCTION

4.3.3 HYDROGEN PRODUCTION

4.4 CONCLUSION

5 GENERAL CONCLUSIONS 


\section{Introduction}

In principle, intense spallation neutron sources can be used not only to irradiate materials (e.g. window materials) and to validate different target geometries/concepts, but also to irradiate fuels (samples, pins or even full assemblies) in order to characterize their behavior under irradiation (essentially in a neutron field).

However, a question arises concerning the representativity of such irradiations. The representativity will of course depend on the phenomena that one tries to understand. Phenomena such as fuel densification, restructuration, redistribution/migration/diffusion of mobile products, gas release etc., will depend strongly on the temperature and temperature gradients, on the flux level and, to a somewhat lesser degree, on the neutron spectrum.

Fuel behavior at high burn-up will essentially depend on the flux level. Fuel-clad interaction and, in general, fuel-clad mechanical behavior will depend mostly on the neutron spectrum, since both neutron damage and Helium production are strongly dependent on it.

The focus of the present note is to document our attempts to understand the phenomena related to the last parameter mentioned above, namely the representativity of an irradiation using an intense spallation source in terms of neutron damage and Helium production.

First, we consider an intense spallation neutron source proposed at CEA, France, as a potential irradiation tool. The source is very intense ( $\sim 40 \mathrm{MW}$ in the proton beam) and capable of providing a flux greater than $5^{*} 10^{15} \mathrm{n} / \mathrm{s} / \mathrm{cm}^{2}$ over a relatively significant volume, with a fast neutron spectrum. Next, we will consider one of the current models for the TMT spallation neutron source of the ADTF program ( 8 MW of beam power).

For both cases we will evaluate neutron flux level and spectrum, damage rates due to protons and neutrons, and Helium production both by protons and neutrons. We will, as much as possible, separate the contribution of high energy $(\mathrm{E}>20 \mathrm{MeV})$ and low energy $(\mathrm{E}<20 \mathrm{MeV})$ neutrons. Some conclusions will be drawn in order to aid in the suggestion of possible ways of optimization the TMT design, should one envisage performing a fuel irradiation in this installation. 


\section{Calculation Methods}

In the present work, the MCNPX Version 2.1.5 Monte Carlo code ${ }^{1}$ was used to assess various physical characteristics of spallation neutron sources. This code handles both low-energy and highenergy particles. In the low energy part of the problem, existing neutron (and partially proton) libraries are used (such as the ENDF/B files). In the present study we used ENDF/B-VI cross sections for all isotopes except natural iron. For this element we employed ENDF/B-V data. In the high-energy range, the MCNPX code uses nuclear model calculations to assess the physics and cross sections of the interactions. The high-energy physics models in MCNPX are, in majority, borrowed from the code LAHET. All our calculations involve sufficient numbers of sampling histories to assure satisfactory statistical behavior of results.

\section{Intense Spallation Neutron Source}

In this chapter we discuss a scoping study of a particular Intense Spallation Neutron Source (ISNS). The geometry chosen for this study is taken from French Commissariat à 1 Energie Atomique design. ${ }^{2}$ The objective was to evaluate general characteristics of such a system. In our work, we assume a proton beam with an intensity of $33 \mathrm{~mA}$ and energy $1.2 \mathrm{GeV}$ per particle. This corresponds to a linear accelerator power of $39.6 \mathrm{MW}$ and surface density of the beam of 58 $\mu \mathrm{A} / \mathrm{cm}^{2}$. These high values were chosen in order to increase neutron fluxes at potential irradiation positions. Protons strike a lead-bismuth eutectic target and produce neutrons by mean of spallation reactions. A single proton of this energy produces, on average, 45 neutrons per spallation. These spallation neutrons could be used for material or fuel irradiation testing, therefore it is important to evaluate:

available neutron fluxes;

the neutron energy spectrum;

heat deposition in the target;

damage and Helium production rates that can be induced at potential irradiation positions in an

ISNS-type of system.

\subsection{Geometry and Composition}

The target, which is a cylinder $125 \mathrm{~cm}$ in radius and $250 \mathrm{~cm}$ in height, is filled with lead-bismuth eutectic (LBE). A window is placed at the center of the cylinder to permit passage of protons to the interior of the target. The window is a cylinder $116 \mathrm{~cm}$ deep, $16 \mathrm{~cm}$ in radius and $0.15 \mathrm{~cm}$ thick. It is made of stainless steel (SS304). The material of the window must be compatible with LBE to avoid eventual corrosion problems. Although the SS304 includes Nickel, an element that is troublesome with regard to compatibility with LBE, its content is insignificant.

The proton beam passes through the conducting window and strikes the target at a depth of approximately $116 \mathrm{~cm}$ from its upper surface. Since the end of the window has a spherical form, the point of impact may vary inside the radius of the beam. This radius is $13.5 \mathrm{~cm}$, being slightly smaller than the size of the window. In this chapter, various characteristics are expressed as a function of $Z$ distance (distance from the upper surface of the target to the point of investigation) and Radial distance (radial distance from the axis of symmetry of the proton beam). Figure 1 illustrates this geometry. Table 1 gives the composition of the materials. An irradiation sample will be placed in the proximity to the conducting window. This must be done at distances that assure the highest possible 
neutron fluxes, hardest neutron spectrum, and that will minimize occurrence of nuclear reactions induced by protons (since we are primarily interested in neutron-induced reactions). At the same time, one should make sure that the irradiation sample does not interfere with the normal LBE flow through the target, for heat removal purposes.

$\begin{array}{lll} & \begin{array}{c}\text { LBE }(44.5 \% \mathrm{~Pb}+55.5 \% \mathrm{Bi}) \\ \text { (atoms/barn/cm) }\end{array} & \begin{array}{c}\text { Stainless steel } 304 \\ \text { (atoms/barn } / \mathrm{cm})\end{array} \\ \mathrm{Pb}^{206} & 3.17495 \mathrm{E}-03 & \\ \mathrm{~Pb}^{207} & 2.91147 \mathrm{E}-03 & \\ \mathrm{~Pb}^{208} & 6.90319 \mathrm{E}-03 & \\ \mathrm{Bi}^{209} & 1.64306 \mathrm{E}-02 & 3.18633 \mathrm{E}-04 \\ \mathrm{C} & & 1.70334 \mathrm{E}-03 \\ \mathrm{Si} & & 6.95028 \mathrm{E}-05 \\ \mathrm{P}^{31} & & 4.47591 \mathrm{E}-05 \\ \mathrm{~S} & & 7.60426 \mathrm{E}-04 \\ \mathrm{Cr} & & 1.46474 \mathrm{E}-02 \\ \mathrm{Cr}^{52} & & 1.66070 \mathrm{E}-03 \\ \mathrm{Cr}^{53} & & 4.12553 \mathrm{E}-04 \\ \mathrm{Cr}^{54} & & 1.74157 \mathrm{E}-03 \\ \mathrm{Mn}^{55} & & 3.38249 \mathrm{E}-03 \\ \mathrm{Fe}^{54} & & 5.33527 \mathrm{E}-02 \\ \mathrm{Fe}^{56} & & 1.22049 \mathrm{E}-03 \\ \mathrm{Fe}^{57} & & 1.62731 \mathrm{E}-04 \\ \mathrm{Fe}^{58} & & 5.56500 \mathrm{E}-03 \\ \mathrm{Ni}^{58} & & 2.12753 \mathrm{E}-03 \\ \mathrm{Ni}^{60} & & 9.21111 \mathrm{E}-05 \\ \mathrm{Ni}^{61} & & 2.92637 \mathrm{E}-04 \\ \mathrm{Ni}^{63} & & 7.41781 \mathrm{E}-05 \\ \mathrm{Ni}^{64} & & 8.76286 \mathrm{E}-02 \\ \mathrm{Total}^{63} & & \\ & & \end{array}$

Table 1 Material compositions for the target and structure of the ISNS. 


\subsection{ISNS physics characteristics}

\subsubsection{Neutron fluxes}

In the Table 2, we give levels of volume-averaged neutron fluxes that are achievable in the LBE target. They are given as a function of the radial distance and the $\mathrm{Z}$ depth into the target. It is seen that most neutrons and, at the same time, most energetic neutrons are produced near the bottom end of the conducting window (approximately $116 \mathrm{~cm}$ in the $\mathrm{Z}$ direction). Neutron fluxes are about an order of magnitude lower at distances $219 \mathrm{~cm}$ deeper than at the point of beam entry and its vicinity. The same conclusion is applicable for fluxes at radial distances greater than $60 \mathrm{~cm}$ from the axis of the proton beam. We conclude that the most of spallation reactions takes place in this zone. The maximum value of the total neutron flux near the window $\mathrm{s}$ bottom is of order of $10^{16} \mathrm{n} / \mathrm{cm}^{2} / \mathrm{s}$. Fluxes of this order can be found at radial distances of about $30 \mathrm{~cm}$, e. g. about $10 \mathrm{~cm}$ from the window s outside cylindrical surface. Nevertheless, the average value of the neutron flux is lower. Neutron fluxes gradually decrease as the distance from the point of entry of the proton beam increases. We also note that non-negligible neutron fluxes are most probably present at $\mathrm{Z}$ distances larger than $250 \mathrm{~cm}$ (target $\mathrm{s}$ total height). Consequently, the size of the target in $\mathrm{Z}$ direction should be increased to avoid any complications of safety/shielding issues that might be related to the presence of high neutron fluxes outside of the target region.

The level of neutron fluxes found in the ISNS system is comparable to the flux level in a typical fast-neutron reactor. Graphical illustrations of the results are given in the Figures 2 and 3. In Figures 4 and 5 we give a global overview of levels of neutron fluxes in the target. Our results are compatible with the values found in Reference 1 .

\begin{tabular}{|c|c|c|c|c|c|c|}
\hline \multicolumn{7}{|c|}{$\mathrm{Z}$ distance $(\mathrm{cm})$} \\
\hline Radial distance $(\mathrm{cm})$ & $0-15$ & $15-30$ & $30-60$ & $60-120$ & $120-180$ & $180-250$ \\
\hline $0-5$ & & & & $1.3 * 10^{16}$ & $1.2 * 10^{16}$ & $2.4^{*} 10^{15}$ \\
\hline $5-15$ & & & & $1.0 * 10^{16}$ & $1.0 * 10^{16}$ & $2.4 * 10^{15}$ \\
\hline $15-30$ & $4.6 * 10^{14}$ & $9.7 * 10^{14}$ & $1.8 * 10^{15}$ & $4.5 * 10^{15}$ & $7.3 * 10^{15}$ & $2.1 * 10^{15}$ \\
\hline $30-45$ & $3.1 * 10^{14}$ & $7.5 * 10^{14}$ & $1.4 * 10^{15}$ & $3.4 * 10^{15}$ & $4.9 * 10^{15}$ & $1.7 * 10^{15}$ \\
\hline $45-60$ & $2.4 * 10^{14}$ & $5.8 * 10^{14}$ & $1.1 * 10^{15}$ & $2.5 * 10^{15}$ & $3.4 * 10^{15}$ & $1.3^{*} 10^{15}$ \\
\hline $60-100$ & $1.3 * 10^{14}$ & $3.3 * 10^{14}$ & $6.3 * 10^{14}$ & $1.3 * 10^{15}$ & $1.7 * 10^{15}$ & $7.0^{*} 10^{14}$ \\
\hline $100-125$ & $3.7 * 10^{13}$ & $9.2 * 10^{13}$ & $1.8 * 10^{14}$ & $3.5 * 10^{14}$ & $4.2 * 10^{14}$ & $1.9 * 10^{14}$ \\
\hline
\end{tabular}

Table 2 Neutron fluxes in the LBE target $\left(\mathrm{n} / \mathrm{cm}^{\wedge} 2 / \mathrm{s}\right)$ 


\subsubsection{Neutron spectrum}

For a study of neutron energy spectrum, we partitioned the energy interval 0-3 GeV into bins, as shown in Table 3. In this table, one finds values of volume-averaged neutron fluxes at different energies and at different radial distances (in annular cylindrical layers). It is seen that the highest fluxes are produced at energies below $20 \mathrm{MeV}$. The fraction of high-energy neutrons (above 20 $\mathrm{MeV}$ ) constitutes, at best, $1.5-2 \%$ of the total, and the highest neutron fluxes with these energies are, in majority, produced near the point of the entry of the proton beam. As neutrons migrate in the diffusive LBE medium, the neutron spectrum becomes softer. A thermal-neutron component (below $0.625 \mathrm{eV}$ ) of the order of $10^{12}-10^{13} \mathrm{n} / \mathrm{cm}^{2} / \mathrm{s}$ appears at large radial distances. We note that, as expected, the energy spectrum of a spallation source is harder than that of a typical fast reactor.

\begin{tabular}{|c|c|c|c|c|c|c|c|}
\hline \multirow{3}{*}{$\begin{array}{c}\text { Energy interval } \\
0-0.625 \mathrm{eV}\end{array}$} & \multicolumn{7}{|c|}{ Radial distance $(\mathrm{cm})$} \\
\hline & $0-5$ & $5-15$ & $15-30$ & $30-45$ & $45-60$ & $60-100$ & $100-125$ \\
\hline & $2.6^{*} 10^{13}$ & $2.6^{*} 10^{13}$ & $2.2 * 10^{13}$ & $2.0 * 10^{13}$ & $1.8 * 10^{13}$ & $1.1 * 10^{13}$ & $3.5 * 10^{12}$ \\
\hline $0.0625 \mathrm{eV}-5 \mathrm{keV}$ & $7.4 * 10^{14}$ & $7.3 * 10^{14}$ & $6.2 * 10^{14}$ & $5.7 * 10^{14}$ & $5.1 * 10^{14}$ & $3.2 * 10^{14}$ & $9.8 * 10^{13}$ \\
\hline $5 \mathrm{keV}-0.907 \mathrm{MeV}$ & $4.5 * 10^{15}$ & $4.2 * 10^{15}$ & $2.7 * 10^{15}$ & $2.0 * 10^{15}$ & $1.4 * 10^{15}$ & $6.6 * 10^{14}$ & $1.6 * 10^{14}$ \\
\hline $0.907 \mathrm{MeV}-20 \mathrm{MeV}$ & $1.7 * 10^{15}$ & $1.3 * 10^{15}$ & $4.3 * 10^{14}$ & $1.7 * 10^{14}$ & $7.3^{*} 10^{13}$ & $1.7 * 10^{13}$ & $2.3^{*} 10^{12}$ \\
\hline $20 \mathrm{MeV}-3 \mathrm{GeV}$ & $1.3 * 10^{14}$ & $9.1 * 10^{13}$ & $1.3 * 10^{13}$ & $3.5^{*} 10^{12}$ & $1.2 * 10^{12}$ & $2.5 * 10^{11}$ & $3.5^{*} 10^{10}$ \\
\hline $\mathrm{E}<20 \mathrm{MeV}$ & $7.0 * 10^{15}$ & $6.3 * 10^{15}$ & $3.8 * 10^{15}$ & $2.8 * 10^{15}$ & $2.0 * 10^{15}$ & $1.0 * 10^{15}$ & $2.6 * 10^{14}$ \\
\hline $\mathrm{E}>20 \mathrm{MeV}$ & $1.3 * 10^{14}$ & $9.1 * 10^{13}$ & $1.3 * 10^{13}$ & $3.5^{*} 10^{12}$ & $1.2 * 10^{12}$ & $2.5 * 10^{11}$ & $3.5 * 10^{10}$ \\
\hline Total & $7.1 * 10^{15}$ & $6.4 * 10^{15}$ & $3.8 * 10^{15}$ & $2.8 * 10^{15}$ & $2.0 * 10^{15}$ & $1.0^{*} 10^{15}$ & $2.6 * 10^{14}$ \\
\hline $\mathrm{E}<20 \mathrm{MeV} /$ Total (\%) & 98.18 & 98.58 & 99.66 & 99.88 & 99.94 & 99.98 & 99.99 \\
\hline $\mathrm{E}>20 \mathrm{MeV} /$ Total $(\%)$ & 1.82 & 1.42 & 0.34 & 0.12 & 0.06 & 0.02 & 0.01 \\
\hline
\end{tabular}

Table 3 Neutron energy spectrum in the LBE target $\left(\mathrm{n} / \mathrm{cm}^{2} / \mathrm{s}\right)$

In conclusion, it is worth mentioning that the highest fluxes and hardest neutron spectra are found in proximity to the window. For this reason, this zone is of particular interest for material testing. Figure 6 illustrates our results.

\subsubsection{Energy deposition}

The distribution of volume-averaged energy deposition in the target is given in the Figure 7. We calculated the energy deposited by all sorts of particles that MCNPX can handle. As expected, the densest volume power is found to be in the regions with the highest neutron fluxes and with neutrons of the highest energies. A maximum value of volume-averaged power density of around $280 \mathrm{~W} / \mathrm{cc}$ must be expected. This value decreases progressively as one moves towards the peripheral regions.

\subsubsection{Damage and Helium production in the window}

Because of the large concentrations of high-energy particles (protons, neutrons and other products of spallation reactions), the damage in the conducting window is important.

There are two major factors that characterize damage to materials. The first factor is related to the fact that atoms of the material are knocked out of their positions in a crystalline lattice. This is usually measured by the number of so-called displacements per atom (dpa). This quantity 
determines how many atoms in the crystalline structure the recoiled first collision atom will eventually knock out. In practice one uses displacement-per-atom cross sections which are then multiplied by the particle flux to give the effective rate of displacements per atom. The second factor is related to the production of gas, such as Helium and Hydrogen, in reactions initiated by neutrons and protons. Hydrogen tends to escape from the lattice. Helium, in turn, can accumulate in clusters inside of the lattice, therefore potentially enhancing swelling of materials. The effect of the presence of Helium on material properties is also temperature dependent.

The relation of these two calculated quantities to the experimentally observed structural properties of materials is still not completely understood, and is typically accounted for through empirical relationships.

We recall that the window is made of stainless steel 304 (SS304). To calculate the damage in the SS304 composition, we must consider the dpa cross sections for all components of this alloy over the whole energy range (0-3 GeV). At high energies, some of these cross sections are missing for materials with minor importance (in particular for $\mathrm{C},{ }^{31} \mathrm{P}, \mathrm{Mn}$ ). Nevertheless, we can estimate the damage in the window by considering it to be made entirely of natural iron instead of accounting for its true composition. Since the most important materials in the window are $\mathrm{Fe}, \mathrm{Ni}$ and $\mathrm{Cr}$, this is a fair approximation; first because iron constitutes around 70\% of SS304 and second because the dpa cross sections for $\mathrm{Ni}$ and $\mathrm{Cr}$ do not differ dramatically from those for $\mathrm{Fe}$.

The damage produced by neutrons was calculated for the whole energy range of interest to this study $(0-3 \mathrm{GeV})$. The dpa cross sections for neutrons come from two different sources. For neutron energies below $20 \mathrm{MeV}$, the calculated with the code SPECTER $^{3}$ dpa cross sections were used. E. Pitcher et al. calculated the high-energy DPA cross sections. ${ }^{4}$ The proton-induced damage calculation was limited by the availability of dpa cross sections. At present time we dispose of these cross sections only in the interval $35 \mathrm{MeV}-3 \mathrm{GeV}$.

We calculated damage and Helium production in the conducting window subdividing it into several cells, as shown in the Figure 8. Table 4 illustrates the damage induced in the window by protons and neutrons, separately, in terms of displacements per atom per year.

$\begin{array}{cccc}Z \text { distance }(\mathrm{cm}) & \text { Neutrons damage (dpa/y) } & \text { Protons damage (dpa/y) } & \text { Total all particles damage (dpa/y) } \\ 0-15 & 4.91 & 0.03 & 4.94 \\ 15-30 & 7.97 & 0.00 & 7.97 \\ 30-60 & 14.62 & 0.00 & 14.62 \\ 60-108.44 & 42.22 & 0.04 & 42.26 \\ 108.44-116 & 140.69 & 29.08 & 169.77\end{array}$

Table 4 Neutron and proton induced damage in the conducting window

(assumed to be entirely made of natural iron).

In the upper part of the window, the damage induced by protons is minimal and it only plays a significant role at the beam-window interface. The damage induced by neutrons is important in all cells. This is related to the fact that significant numbers of neutrons that are scattered in the target hit the window from inside. In the vicinity of the beam-target interface (where the majority of the highenergy neutrons are produced) the dpa rate in the window is high and reaches a value of $170 \mathrm{dpa} / \mathrm{y}$.

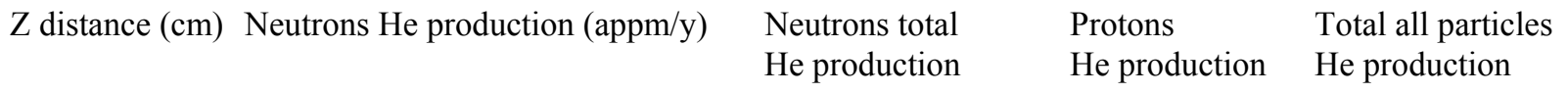




$\begin{array}{llllll} & & & \text { appm/y } & \text { appm/y } & \text { appm/y } \\ 0-15 & \mathrm{E}<20 \mathrm{Mev} & 20 \mathrm{MeV}<\mathrm{E}<3 \mathrm{GeV} & & & \\ 15-30 & 6.06 & 1.51 & 7.56 & 0.89 & 8.45 \\ 30-60 & 4.78 & 0.63 & 5.41 & 0.00 & 5.41 \\ 60-108.44 & 10.93 & 2.22 & 13.16 & 0.12 & 13.28 \\ 108.44-116 & 52.96 & 10.95 & 63.91 & 0.77 & 64.68 \\ & 539.96 & 126.13 & 666.09 & 3950.76 & 4616.85\end{array}$

Table 5 Neutron- and proton-induced Helium production in the conducting window (assumed to be made entirely of natural iron).

The dpa proton rate in the window is lower than the one due to neutrons. This is due to the high energies the incident protons. At these energies, protons lose energy mostly by interaction with the electron clouds of the window $\mathrm{s}$ atoms.

Helium production by protons in the window is also very high (Table 5). The maximum value is around $3950 \mathrm{appm} / \mathrm{y}$. We note that in reference Error! Bookmark not defined. the Helium production induced by protons is apparently underestimated by approximately a factor of two.

\subsection{Irradiation of natural iron sample in the ISNS}

\subsubsection{Neutron and proton induced damage in the irradiation zone}

As was mentioned previously, the highest neutron fluxes are observed at distances up to about 30 $\mathrm{cm}$ from the beam line of symmetry. On the other hand, if for an irradiation of fuel and clad material one is primarily interested in damage produced by neutrons, the influence of the proton-related reactions must be kept at a minimum in the zone of irradiation. As discussed in Reference Error! Bookmark not defined., the fraction of reactions induced by protons at radial distances exceeding $25 \mathrm{~cm}$ is negligible.

Therefore, in the following discussion we consider an irradiation sample situated at a radial distance of $26.15 \mathrm{~cm}$. The authors of the Reference Error! Bookmark not defined. also estimate positioning of the irradiation sample at these distances will not interfere with the flow of LBE through the target, as needed to remove excessive heat from the system. The simulated irradiation zone is bulk natural iron with dimensions $1 \times 1 \times 40 \mathrm{~cm}$. Figure 1 and 14 illustrate the geometry. As previously indicated, damage was calculated in the energy range 0-3 GeV for neutrons and $35 \mathrm{MeV}$ $3 \mathrm{GeV}$ for protons. The following Table 6 illustrates our results. At radial distances exceeding 25 $\mathrm{cm}$, the proton-induced damage was found to be negligible, therefore the results are not listed here. In the same zone, the neutron damage constitutes several dozen dpa/y, nevertheless being lower than damage induced in window. In the Figures 9, we give a graphical representation of our results. The average neutron damage rate over the entire volume of the irradiation sample is $66 \mathrm{dpa} / \mathrm{y}$

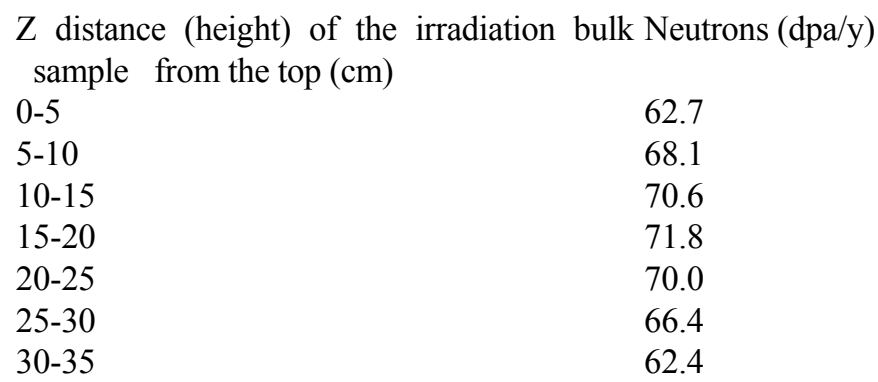


Table 6 Neutron induced damage in the natural Fe irradiation sample

\section{Helium production in the irradiation zone}

we mentioned previously, Helium production is an important parameter to assess in considering damage in materials. The bution to Helium production comes from $(\mathrm{n}, \alpha)$ and $\left(\mathrm{n},{ }^{3} \mathrm{He}\right)$ reactions. The thresholds of these reactions are at about several $\mathrm{MeV}$, ponding cross sections tend to saturate and remain approximately constant at higher energies. Therefore, it is very important to acc ht for reactions taking place at high-energies since even a small fraction of high-energy particles in the sample might generate im f Helium production.

ENDF/B-V library for natural iron was used to calculate Helium production at low neutron energies (below $20 \mathrm{MeV}$ ). At higher e $3 \mathrm{GeV}$ ), the tabulated cross-sections provided by Los Alamos National Laboratory were used. ${ }^{5}$ The rate of Helium production by $\mathrm{p}$ alculated in the energy interval $20 \mathrm{MeV}-3 \mathrm{GeV}$, which is the current limitation for available He production data. We mention that the results on Helium production are most probably underestimated. This is due to the fact that in the energy range $20-150 \mathrm{MeV}$ t 0 evaluations predict higher $(\mathrm{n}, \alpha)$ and $\left(\mathrm{n},{ }^{3} \mathrm{He}\right)$ cross sections than the set of nuclear data used in this work. Table 7 gives separate rate of Helium production by low and high-energy neutrons. Figure 10 illustrates this table.

$\begin{array}{llll}Z \text { distance (height) of the irradiation Neutrons } & \text { Neutrons } & \text { Neutrons total } \\ \text { bulk sample from the top }(\mathrm{cm}) & \mathrm{E}<20 \mathrm{MeV} & 20 \mathrm{MeV}<\mathrm{E}<3 \mathrm{GeV} & \\ 0-5 & 26.7 & 18.2 & 44.9 \\ 5-10 & 26.6 & 26.3 & 52.9 \\ 10-15 & 27.6 & 30.4 & 58.0 \\ 15-20 & 25.0 & 33.5 & 58.6 \\ 20-25 & 28.4 & 36.9 & 65.3 \\ 25-30 & 26.2 & 33.3 & 59.5 \\ 30-35 & 22.8 & 33.6 & 56.4 \\ 35-40 & 17.2 & 27.9 & 45.1\end{array}$

Table 7 Helium production rate by neutrons of low- and high-energy in natural Fe irradiation sample (appm/y)

We have mentioned that high-energy neutrons might be very important in terms of He production. At the irradiation position, the flux of these high-energy neutrons $(\mathrm{E}>20 \mathrm{MeV})$ is lower than the flux of neutrons with energies $<20 \mathrm{MeV}$ by approximately two orders of magnitude. At this position, the number of high-energy neutrons constitutes, at best, a fraction of a percent of the total neutron flux. Nevertheless, Table 7 clearly indicates that He production by these neutrons is important all along the sample in the $\mathrm{Z}$ direction. The average Helium production rate over the whole volume of the irradiation sample is $25.1 \mathrm{appm} / \mathrm{y}$ for low-energy neutrons and $30 \mathrm{appm} / \mathrm{y}$ for high-energy neutrons.

Since the proton-induced Helium production at irradiation position was found to be non-significant, we do not list these results here. These results were expected since the sample was intentionally placed at distances that assure that only a small fraction of nuclear reactions will be induced by protons.

Finally, since an indicator of the representativity of an irradiation is the ratio of Helium production in a sample to the induced dpa rate (appm/dpa), Table 8 gives the values of this ratio for the bulk irradiation sample of natural Fe:

$\begin{array}{ll}Z \text { distance }(\mathrm{cm}) & \begin{array}{l}\text { He production/damage } \\ \text { appm/dpa }\end{array} \\ 0-5 & 0.72\end{array}$




$\begin{array}{ll}5-10 & 0.78 \\ 10-15 & 0.82 \\ 15-20 & 0.82 \\ 20-25 & 0.93 \\ 25-30 & 0.90 \\ 30-35 & 0.90 \\ 35-40 & 0.80\end{array}$

Table 8 Ratio of the total Helium production to the total damage in the natural Fe irradiation sample

at chosen irradiation positions are found to be relatively close to what is typically observed in a fast-reactor spectrum for a ferriti around 0.5 ). The average value of this ratio over the whole irradiation volume is 0.83 .

\section{Conclusion}

ere found to be in global agreement, with respect to the general characteristics of the spallation source (neutron fluxes, energy spect g window, etc.), with the work in Reference Error! Bookmark not defined.. As far as damage at potential irradiation positions, $v$ of the order of 0.7-0.95 These values, which are higher than the values observed in a typical fast reactor, are the result of a re eutrons with $\mathrm{E}>20 \mathrm{MeV}$. On the other hand, the proton contribution can be kept small by an appropriate positioning of the irradiatio

\section{Irradiation study of Iron in the ADTF TMT facility}

f this chapter is estimation of the level of radiation damage and gas production that one can expect in one of the current ADTF s Alamos National Laboratory, and comparison of these parameters with ones obtained for the ISNS. The spallation neutron sourc n a $600-\mathrm{MeV}$ proton beam with an intensity of $13.3 \mathrm{~mA}$. The MCNPX code is used to address various physical characteristics of th xpected radiation damage and gas production in an irradiation sample. 


\section{Geometry}

is illustrated in Figure 11. This geometry was taken partially from a recent Los Alamos National Laboratory design. ${ }^{6}$ Rastered in bo proton beam with intensity of $13.3 \mathrm{~mA}$ strikes a Lead-Bismuth Eutectic (LBE) target and produces neutrons via spallation reaction $\mathrm{d}$ within tubes of $2.05 \mathrm{~cm}$ in radius and $2000 \mathrm{~cm}$ in length. In total, the target contains 20 such tubes distributed along the proton be e nearly uniform neutron flux. The proton beam is $5.3 \mathrm{~cm}$ wide (X direction) and $38 \mathrm{~cm}$ long (in Y direction). We refer to Refer defined. for the details of physical characteristics of this system.

LBE tubes are confined between two bulk components $(18.325 \times 200 \times 62 \mathrm{~cm})$ of reflector material containing Nickel, in order to spallation neutrons. Three irradiation samples are placed inside one of these bulk objects. Each sample is a parallelepiped $1 \mathrm{x} 1 \mathrm{x}$ Figure 11 illustrates the placement of the samples and Figure 14 describes the partitioning of the sample volumes into cells. ters of the samples is $10 \mathrm{~cm}$.

e study was to analyze the damage produced at potential irradiation positions and to optimize their placement if necessary.

\section{Neutron fluxes and spectrum}

lux is calculated over a $\sim 9$-liter volume in the reflector (parallelepiped $11.375 \times 40 \times 20 \mathrm{~cm}$ ). Subdivision of this volume into lay irection is used to define the spatial distribution of the neutron flux. The maximum neutron flux over 9-liter volume is about $6^{*}$ eutron fluxes as a function of layer thickness as one moves in the $\mathrm{X}$ direction from the origin. The neutron flux is given separately $(>20 \mathrm{MeV})$ energies. We can see from this table that the high-energy component of the flux is about $2 \%$. This result is consis tion of this fraction for the ISNS. In Figure 12 we give a global overview of the neutron flux in the target. Figure 13 illustrates our $r$ the reflector.

$\begin{array}{lllll}\left.\text { Thickness (from } \mathrm{x}_{1} \text { to } \mathrm{x}_{2}, \mathrm{~cm}\right) & \mathrm{E}<20 \mathrm{MeV} & 20 \mathrm{MeV}<\mathrm{E}<3 \mathrm{GeV} & \%<20 & \%>20 \\ 6.675-8 & 1.3^{*} 10^{14} & 3.7 * 10^{12} & 97.2 & 2.8 \\ 8-10 & 1.2^{*} 10^{14} & 3.0^{*} 10^{12} & 97.5 & 2.5 \\ 10-12 & 1.1^{*} 10^{14} & 2.5^{*} 10^{12} & 97.7 & 2.3 \\ 12-14 & 9.4^{*} 10^{13} & 2.1 * 10^{12} & 97.8 & 2.2 \\ 14-16 & 8.2^{*} 10^{13} & 1.7 * 10^{12} & 97.9 & 2.1 \\ 16-18.25 & 5.7 * 10^{13} & 1.4^{*} 10^{12} & 97.7 & 2.3\end{array}$

Table 9 Neutron flux in the 9 -liter volume in the reflector $\left(\mathrm{n} / \mathrm{cm}^{2} / \mathrm{s}\right)$

from our study the total neutron flux (over the whole energy range $20 \mathrm{MeV}<\mathrm{E}<3 \mathrm{GeV}$ ) at the irradiation position, in the case -4 times lower that fluxes at irradiation position in the case of the ISNS. Therefore, we expect that the neutron-induced damage $i$ the same factor. For Helium production, the rate is sensitive to the high-energy neutrons in the spectrum, it will not necessarily fol se of TMT, the fraction of high-energy neutrons $(>20 \mathrm{MeV})$ and their flux at irradiation positions are higher than in the ISNS cas efore, the Helium production in these two cases will differ by a smaller factor.

\section{Irradiation of Iron in the TMT}

\section{Neutron and proton induced damage at irradiation positions}

ced damage was calculated for all three irradiation positions (described here as samples ) using the following set of dpa cross s below $20 \mathrm{MeV}$, the results from the code SPECTER were used; for neutron energies above $20 \mathrm{MeV}$ (up to $3 \mathrm{GeV}$ ) the results fi tilized. The results of our calculations are presented in the Table 10. Figure 15 illustrates this table. 


$\begin{array}{cccc}\text { Sample } & & \\ \text { Height of samples (cm) } & 1 & 2 & 3 \\ 0-5 & 14.27 & 12.02 & 7.81 \\ 5-10 & 18.01 & 15.08 & 9.76 \\ 10-15 & 20.57 & 16.76 & 10.93 \\ 15-20 & 21.25 & 18.02 & 11.83 \\ 20-25 & 21.13 & 18.05 & 11.81 \\ 25-30 & 19.99 & 17.25 & 10.98 \\ 30-35 & 18.12 & 15.48 & 9.77 \\ 35-40 & 14.28 & 12.08 & 7.77\end{array}$

Table 10 Neutron induced damage in the irradiation samples (dpa/y)

It is seen from the Table 10 that sample 1 exhibits the highest rate of damage due to the fact that most protons at the middle of the tube array interact with LBE by mean of spallation reactions. The region between the first and second samples should also be studied in more detail to select positions with maximum neutron fluxes. Nevertheless, we should not expect to be able to reduce the damage rate significantly.

Proton-induced damage was calculated only in the energy interval $35 \mathrm{MeV}<\mathrm{E}<3 \mathrm{GeV}$, due to the unavailability of dpa cross sections at low proton energies. Table 11 indicates the levels of damage induced by protons in all three irradiation samples. Figure 16 illustrates this table.

\begin{tabular}{cccc} 
& \multicolumn{3}{c}{ Sample } \\
Height of samples (cm) & 1 & 2 & 3 \\
$0-5$ & 0.17 & 0.32 & 0.43 \\
$5-10$ & 0.23 & 0.37 & 0.64 \\
$10-15$ & 0.24 & 0.45 & 0.67 \\
$15-20$ & 0.28 & 0.37 & 0.73 \\
$20-25$ & 0.26 & 0.41 & 0.63 \\
$25-30$ & 0.29 & 0.40 & 0.66 \\
$30-35$ & 0.23 & 0.36 & 0.56 \\
$35-40$ & 0.16 & 0.25 & 0.41
\end{tabular}

Table 11 Proton induced damage in the irradiation samples (dpa/y)

\section{Helium production}

n production by neutrons of low $(\mathrm{E}<20 \mathrm{MeV})$ and high $(20 \mathrm{MeV}<\mathrm{E}<3 \mathrm{GeV})$ energies is given in Table 12 separately for each sar rgies, the ENDF/B-V library was used; at high energies the Los Alamos National Laboratory evaluations were utilized.

\begin{tabular}{llllllllll} 
& \multicolumn{3}{l}{ sample 1 } & \multicolumn{3}{c}{ sample 2 } & \multicolumn{3}{c}{ sample 3 } \\
Height of samples $(\mathrm{cm})$ & $<20 \mathrm{MeV}$ & $>20 \mathrm{MeV}$ & Total & $<20 \mathrm{MeV}$ & $>20 \mathrm{MeV}$ & Total & $<20 \mathrm{MeV}>20 \mathrm{MeV}$ & Total \\
$0-5$ & 23.76 & 26.42 & 50.18 & 18.83 & 27.73 & 46.56 & 12.44 & 24.06 & 36.50 \\
$5-10$ & 28.28 & 34.83 & 63.12 & 23.87 & 37.69 & 61.56 & 15.31 & 28.82 & 44.13 \\
$10-15$ & 32.36 & 40.88 & 73.24 & 24.37 & 42.32 & 66.69 & 17.35 & 33.12 & 50.48 \\
$15-20$ & 33.49 & 42.13 & 75.62 & 28.36 & 47.53 & 75.90 & 20.90 & 38.43 & 59.33 \\
$20-25$ & 34.77 & 42.66 & 77.43 & 31.67 & 47.21 & 78.88 & 18.37 & 37.35 & 55.72 \\
$25-30$ & 29.13 & 40.68 & 69.82 & 27.17 & 45.23 & 72.39 & 15.60 & 34.87 & 50.48 \\
$30-35$ & 30.08 & 36.90 & 66.98 & 25.86 & 40.80 & 66.66 & 14.06 & 30.77 & 44.83
\end{tabular}


Table 12 Helium production by neutrons in the irradiation samples (appm/y)

As expected, by analogy with the neutron-induced damage rate case, most of the Helium production occurs in regions with the highest neutron fluxes. It is also seen that high-energy neutrons contribute significantly to the total Helium production, even though they constitute only a small fraction (few \%) of the total neutron flux. Figures 17, 18 and 19 give the levels of Helium production in each sample.

Table 13 shows the Helium production rates induced by protons with energies $20 \mathrm{MeV}<\mathrm{E}<3$ $\mathrm{GeV}$. Figure 20 illustrates this table.

$\begin{array}{llll} & \text { Sample } & & \\ \text { Height of samples }(\mathrm{cm}) & 1 & 2 & 3 \\ 0-5 & 5.32 & 10.75 & 15.27 \\ 5-10 & 6.99 & 12.12 & 22.00 \\ 10-15 & 7.30 & 14.15 & 23.26 \\ 15-20 & 8.53 & 12.04 & 24.63 \\ 20-25 & 7.71 & 12.47 & 21.61 \\ 25-30 & 8.80 & 12.63 & 22.67 \\ 30-35 & 7.25 & 11.57 & 18.87 \\ 35-40 & 4.93 & 8.19 & 14.26\end{array}$

Table 13 Helium production by protons in the irradiation samples (appm/y)

Proton-induced Helium production in the samples is significant, and it reaches value of $9 \%$ for the first sample and value of $30 \%$ for the sample 3 of the total Helium production. Since Helium production is considered to be an important component of the experimentally observed and empirically described material damage, the irradiation sample must be placed in regions with low proton flux to stay representative of damages mostly due to neutrons. As seen from the Table 13, these regions are situated between the first and second samples. Nevertheless, even in these regions the fraction of proton-induced reactions is unacceptably significant. Care should be taken to minimize these kinds of reactions. To eliminate the undesired fraction of protons that do not interact in LBE tubes, one might consider increasing the zone where the spallation reactions take place. Care should be taken, however, not to introduce any material that will absorb or diffuse neutrons out of the regions of interest. Proton-induced damage evidently follows a different trend than the damage induced by neutrons as one moves along positions 1, 2 and 3. Most of protons interact in the first LBE tubes, thereby minimizing proton-induced reactions in the irradiation positions that are placed in front of the first layers of these tubes. As one moves to positions 2 and 3, one find a bigger fraction of protons that do not contribute to spallation reactions, inducing more undesired reactions at irradiation positions.

Finally, as in the case of the ISNS, we give the ratio of neutron-induced Helium production in a sample to the neutron-induced dpa rate (appm/dpa). Table 14 gives values of this ratio for each irradiation sample separately. It is seen that the appm/dpa ration is high and does not reproduce the irradiation conditions typically present in a fast reactor. 


$\begin{array}{llll}\text { Height of samples }(\mathrm{cm}) & 1 & 2 & 3 \\ 0-5 & 3.52 & 3.88 & 4.67 \\ 5-10 & 3.50 & 4.08 & 4.52 \\ 10-15 & 3.56 & 3.98 & 4.62 \\ 15-20 & 3.56 & 4.21 & 5.01 \\ 20-25 & 3.66 & 4.37 & 4.72 \\ 25-30 & 3.49 & 4.20 & 4.60 \\ 30-35 & 3.70 & 4.31 & 4.59 \\ 35-40 & 3.53 & 3.84 & 4.19\end{array}$

Table 14 Ratio of He production induced by neutrons to neutron damage (appm/dpa)

\subsubsection{Hydrogen production}

Hydrogen production by neutrons of low-energy $(\mathrm{E}<20 \mathrm{MeV})$ is given in Table 15 separately for each sample. At low energies, the ENDF/B-V library was used, at high energies, the Los Alamos National Laboratory evaluations were utilized. At high neutron energies $(>20 \mathrm{MeV})$, Hydrogen production was found to be negligible, therefore Table 15 lists the total hydrogen production. Figure 21 illustrates our results.

\begin{tabular}{llll} 
& \multicolumn{3}{c}{ Sample } \\
Height of samples $(\mathrm{cm})$ & 1 & 2 & 3 \\
$0-5$ & 88.63 & 68.57 & 41.61 \\
$5-10$ & 108.75 & 85.02 & 53.81 \\
$10-15$ & 128.23 & 92.87 & 60.25 \\
$15-20$ & 129.04 & 99.93 & 71.59 \\
$20-25$ & 131.03 & 108.49 & 64.98 \\
$25-30$ & 120.52 & 97.79 & 59.51 \\
$30-35$ & 114.14 & 93.51 & 50.45 \\
$35-40$ & 85.27 & 66.66 & 41.76
\end{tabular}

Table 15 Hydrogen production by neutrons (appm/y)

As seen the Hydrogen production induced by neutrons exceeds the total Helium production by a factor of approximately 2 . Nevertheless, from a material testing point of view, the Hydrogen production is less troublesome because of the low mass of $\mathrm{H}$ atoms, and, therefore, their high ability to escape from crystalline lattices.

Hydrogen production by protons is negligible (rates about $10^{-4} \mathrm{appm} / \mathrm{y}$ ), and, thus, not shown here.

\subsection{Conclusion}

The maximum Helium production rates are found to be of the order of $70-80 \mathrm{appm} / \mathrm{y}$ at the potential irradiation positions for the TMT model that we have analyzed here. The corresponding neutron damage rate reaches a value of approximately $20 \mathrm{dpa} / \mathrm{y}$. Gas production due to protons has been found to be significant due to the LBE target geometry. In fact, protons are responsible for the $9 \%$ to $30 \%$ of the total Helium production, even if only about $1 \%$ of the atom displacements is due to protons. Proton-induced reactions in irradiation samples could be eliminated by target geometry changes, without reducing the neutron flux level at the irradiation position. These two conflicting objectives are obviously difficult to meet without a substantial increase in the beam power value. 


\section{General conclusions}

The results in the present paper confirm that to obtain reasonable irradiation conditions (e. g. for transmutation dedicated fuels), one needs a very intense proton beam, with a power higher than 30 $40 \mathrm{MW}$. This high power allows one to produce both a high neutron flux level $\left(>5 * 10^{15} \mathrm{n} / \mathrm{s} / \mathrm{cm}^{2}\right)$ over a relatively significant volume (without strong spatial gradients), and to produce a fairly representative ratio between Helium production and damage in terms of dpa. This last result is due to the fact that one can choose a geometrical arrangement of the irradiation zone inside the overall target volume that minimizes both the high energy neutrons and, in particular, the proton interactions at the irradiation positions. Helium production is strongly reduced with respect to the case where the irradiation position is kept very close to the spallation target, to avoid neutron flux level degradation. These results indicate the probable limitations of an irradiation capacity as a simple function of the proton beam power.

\section{References}

1. Laurie S. Waters, editor,

$M C N P X^{T M}$ user s manual, version 21.5

Report TPO-E83-G-UG-X-00001, Los Alamos National Laboratory, 1999

2. P. Deffain and J. Bergeron

Evaluation d une source de neutrons de spallation multifilières pour des irradiations à hauts flux

Report CEA/SERMA/LCA/RT/98-2210/A, 1998.

L. R. Greenwood and R. K. Smither

SPECTER: Neutron damage calculations for material irradiations

report ANL/FPP/TM-1987, 1997.

E. J. Pitcher et all.

The effect of the new nucleon-nucleus elastic scattering data in LAHET ${ }^{T M}$ version 2.8 on neutron displacement cross sections evaluations

Proceedings of the symposium on materials for spallation sources, Orlando, FL, USA, February 10-12, 1997.

E. Pitcher

Private communication.

E. Pitcher

Physics analysis of the ADTF TMT

AAA-CEA collaboration meeting, June 18-21, 2001 


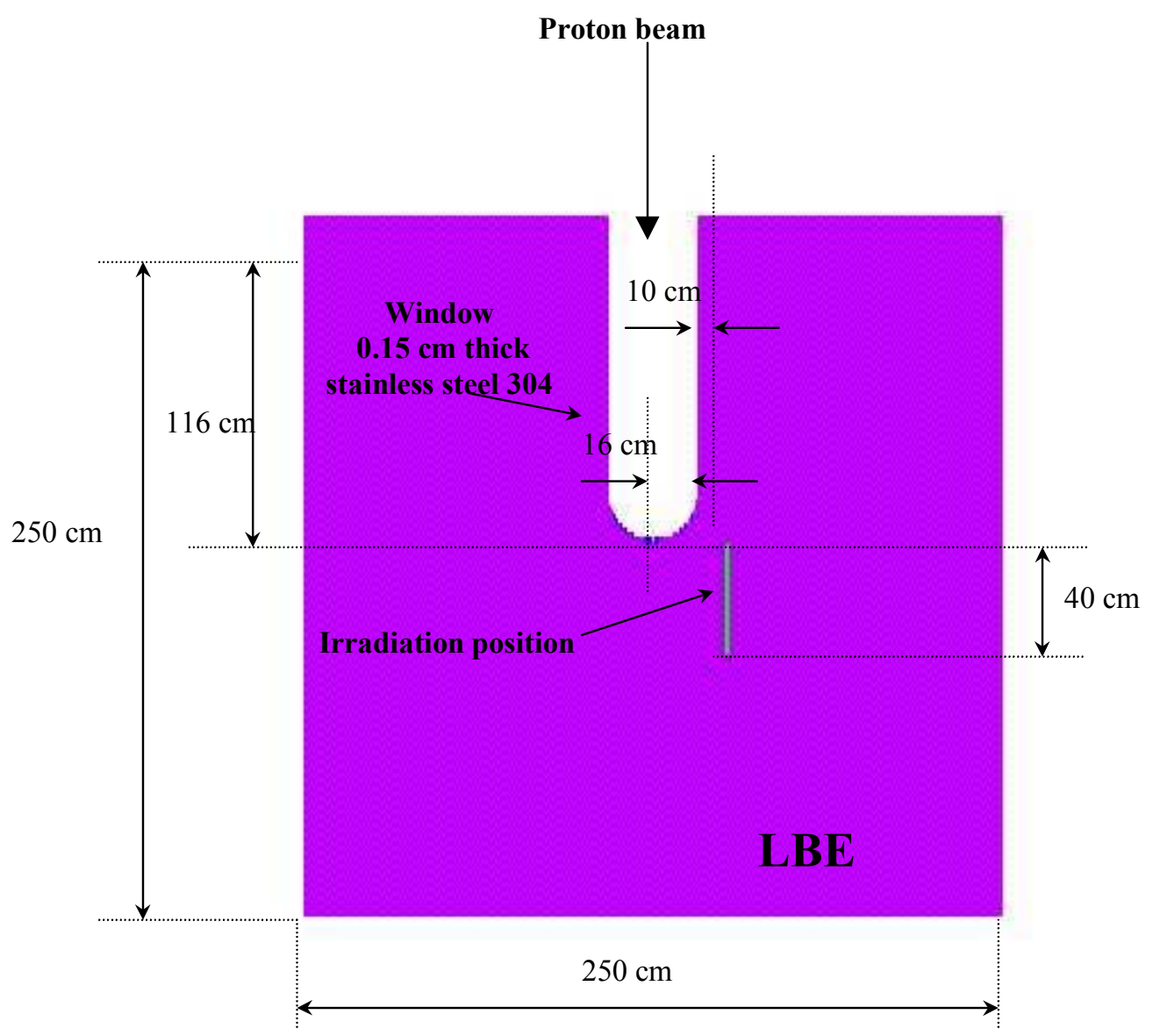

Figure 1 Geometry of the ISNS 


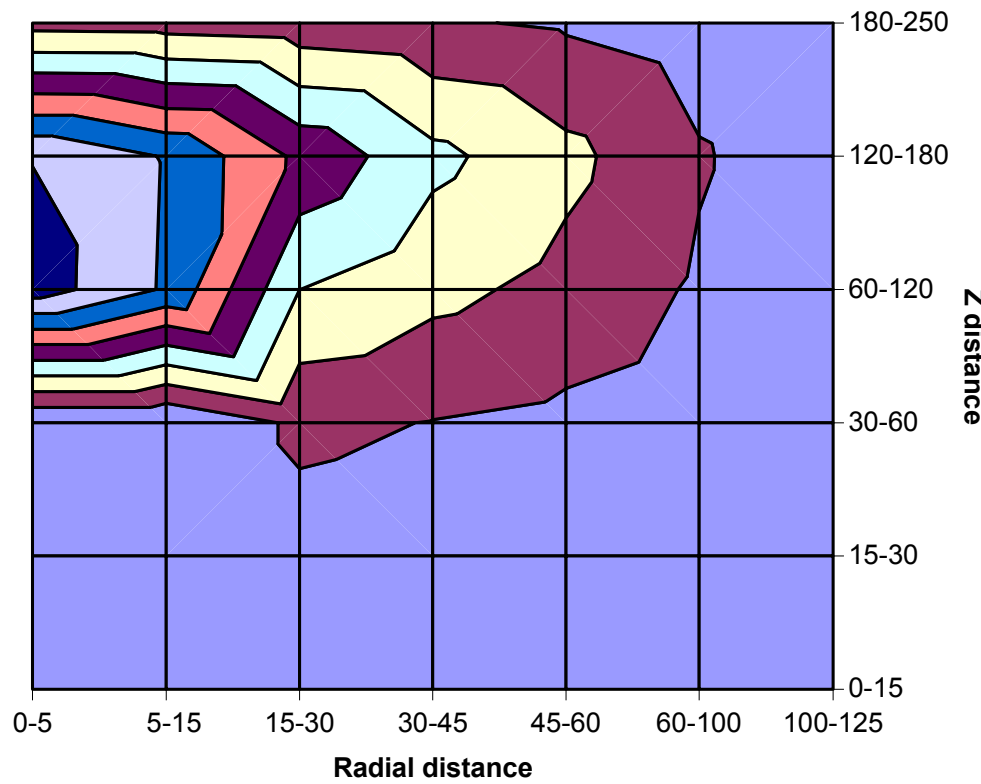

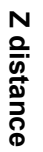

$\square 0.0000 \mathrm{E}+00-1.5000 \mathrm{E}+15 \square 1.5000 \mathrm{E}+15-3.0000 \mathrm{E}+15 \square 3.0000 \mathrm{E}+15-4.5000 \mathrm{E}+15$ $\square 4.5000 \mathrm{E}+15-6.0000 \mathrm{E}+15 \square 6.0000 \mathrm{E}+15-7.5000 \mathrm{E}+15 \square 7.5000 \mathrm{E}+15-9.0000 \mathrm{E}+15$ $\square 9.0000 \mathrm{E}+15-1.0500 \mathrm{E}+16$ - $1.0500 \mathrm{E}+16-1.2000 \mathrm{E}+16$-1.2000E+16-1.3500E+16

Figure 2 Neutron fluxes $\left(\mathrm{n} / \mathrm{cm}^{2} / \mathbf{s}\right)$ in the ISNS target (surface view)

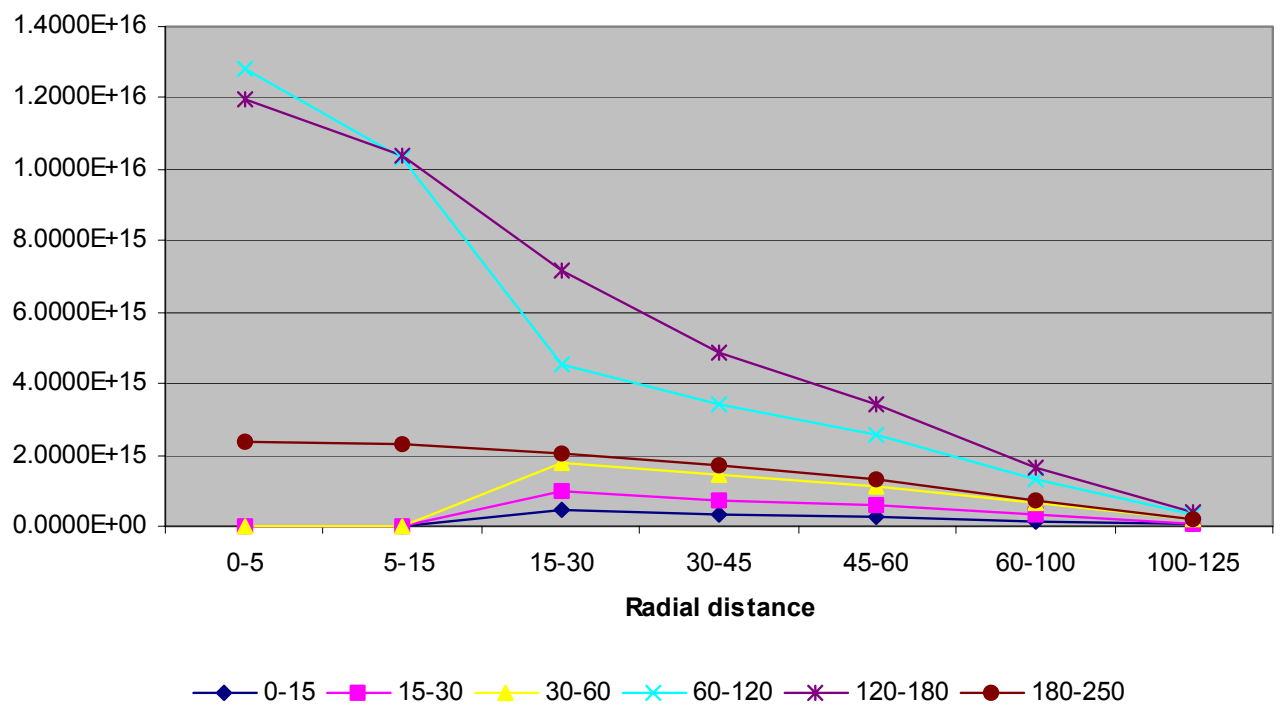

Figure 3 Neutron fluxes $\left(\mathrm{n} / \mathrm{cm}^{2} / \mathbf{s}\right)$ in the ISNS target (planar view) 


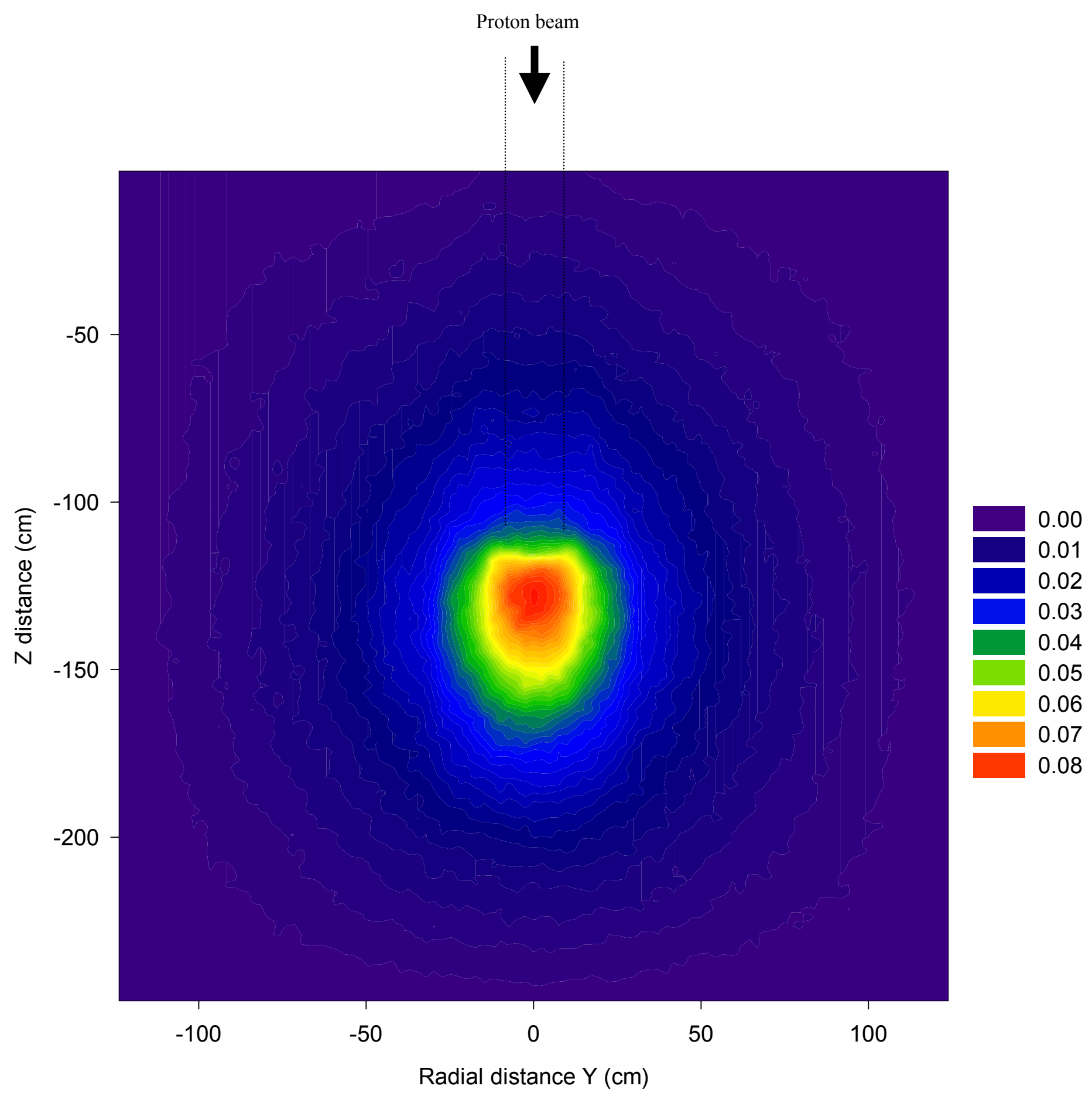

Figure 4 Global view of neutron fluxes in the ISNS as a function of $Z$ and radial distance (in $Y$ direction). Flux is given in units neutrons per $\mathrm{cm}^{2}$ per second per incident proton. 


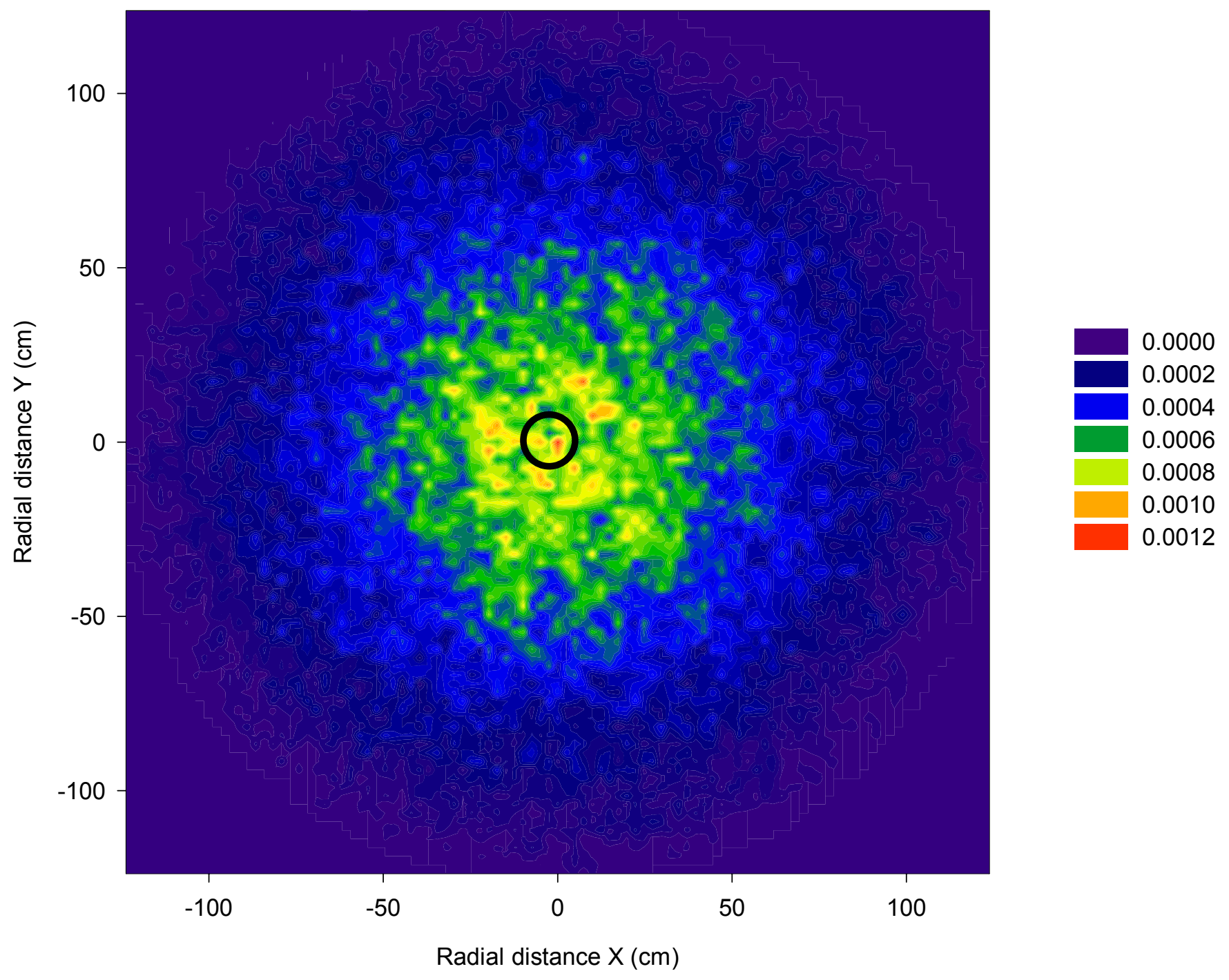

Figure 5 Global view of neutron fluxes in the ISNS as a function of radial distances in $Y$ and $X$ directions. Flux is given in units neutrons per $\mathbf{c m}^{2}$ per second per incident proton. 


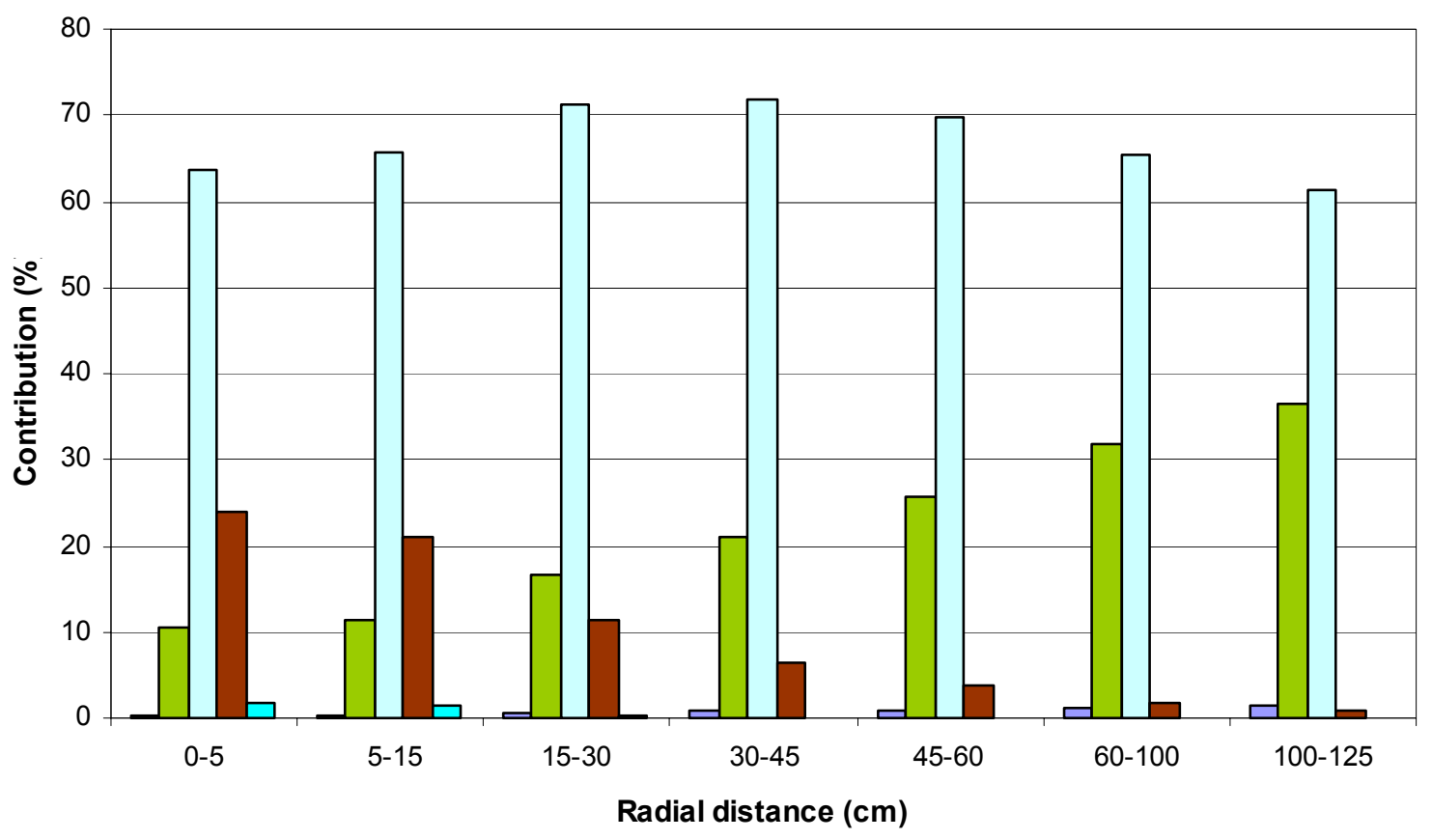

$\square$ 0-0.625 eV $\square 0.0625$ eV-5 keV $\square 5$ keV-0.907 MeV $\square 0.907$ MeV-20 MeV $\square 20 \mathrm{MeV}-3 \mathrm{GeV}$

Figure 6 Neutron energy spectrum in the ISNS

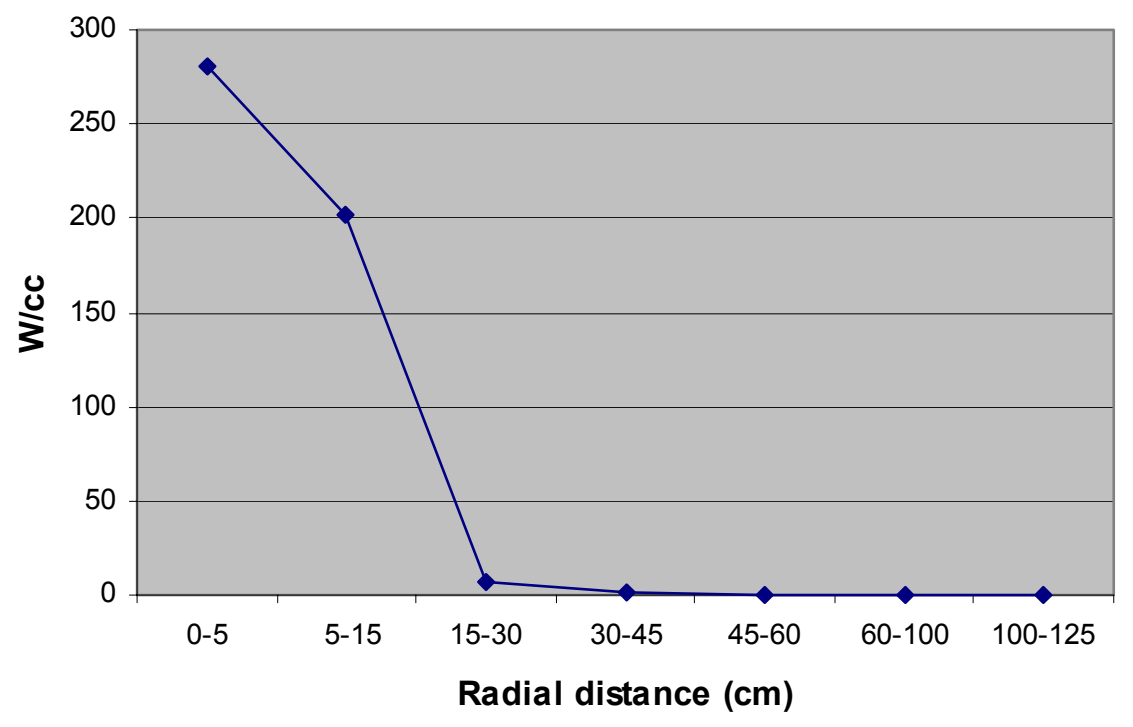

Figure 7 Heat deposition in the ISNS target 


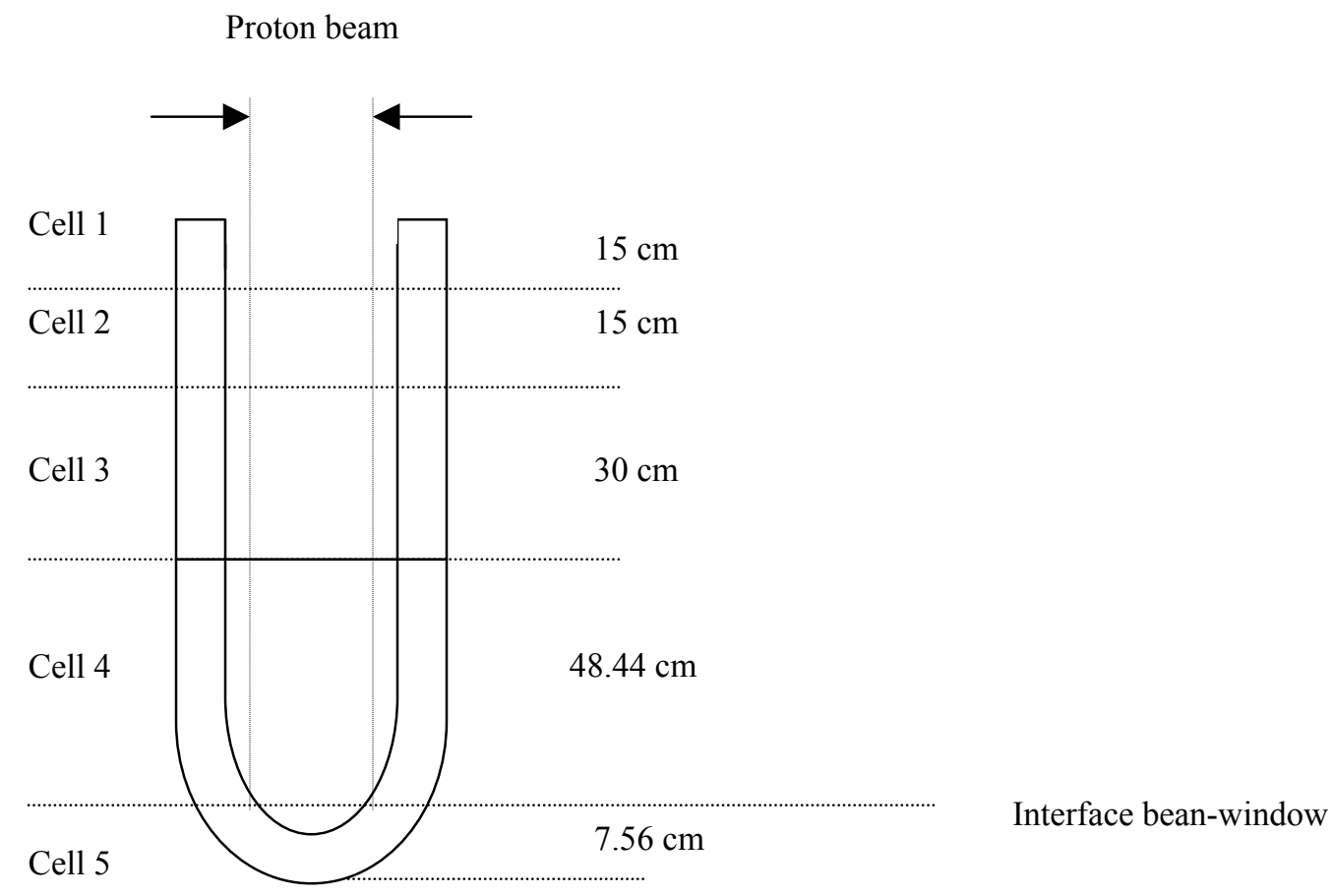

Figure 8 Partitioning of the ISNS window

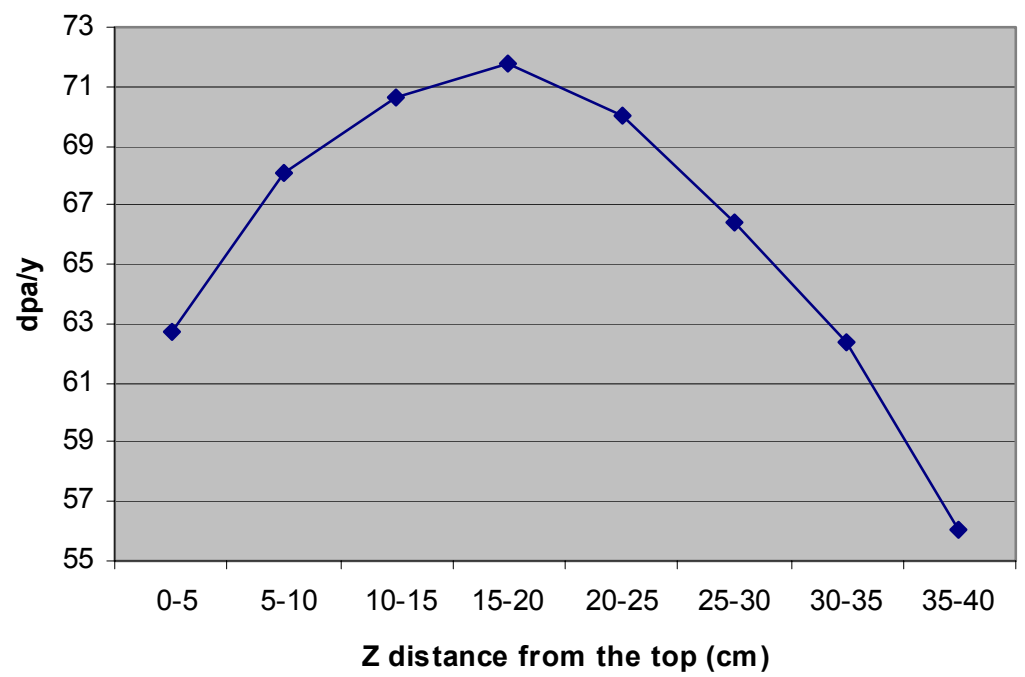

Figure 9 Neutron damage in the irradiation sample (ISNS case) 


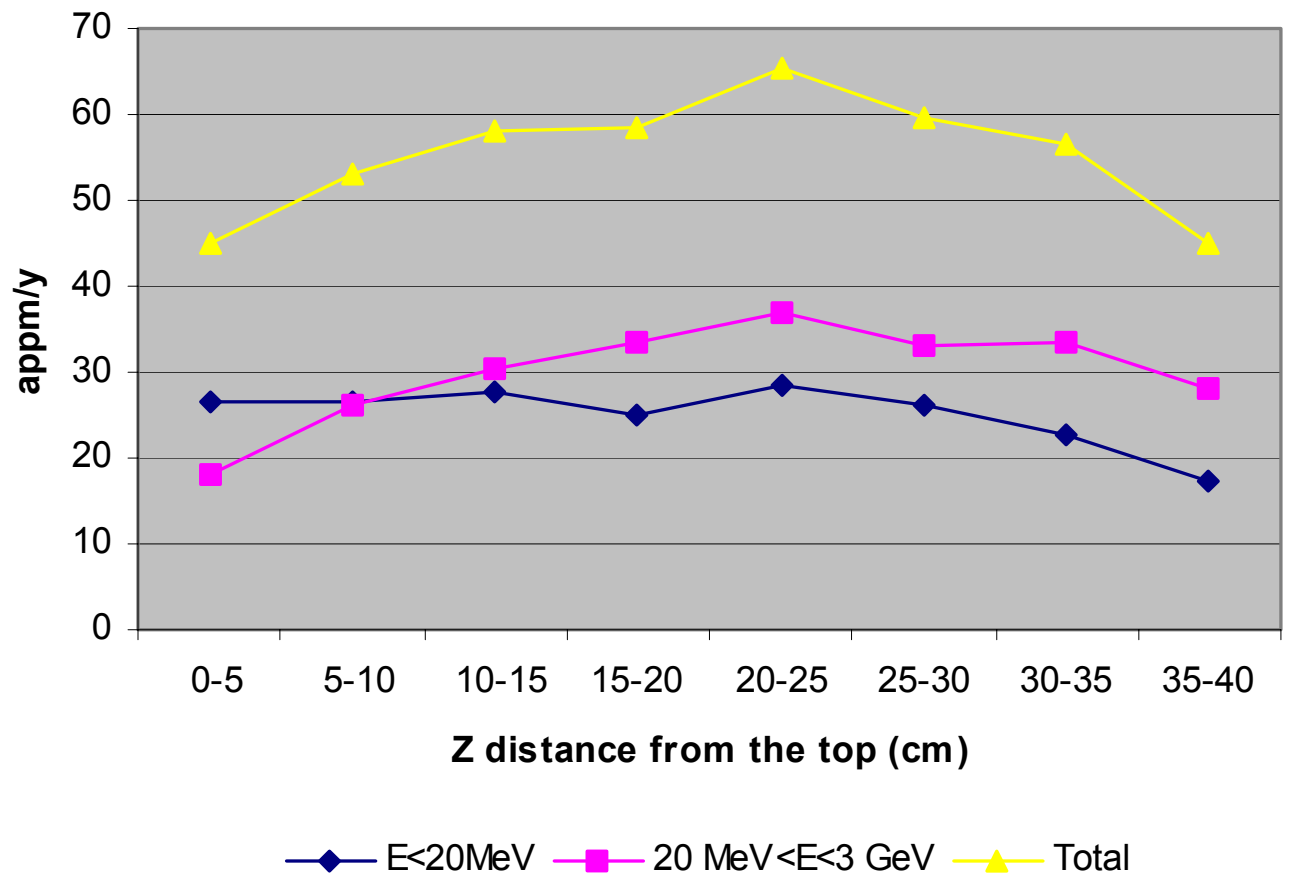

Figure 10 Helium production by neutrons in the irradiation sample (ISNS case) 


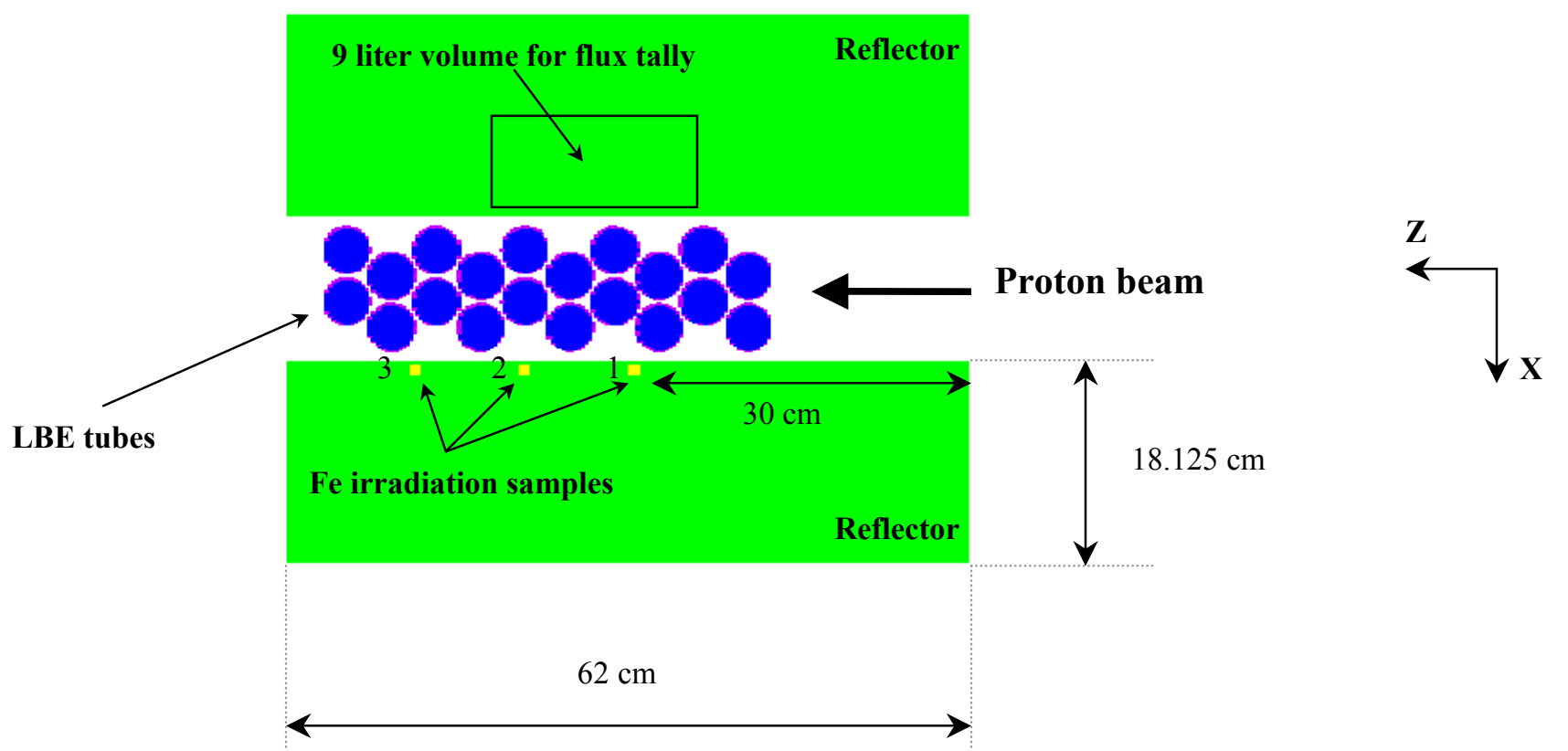

Figure 11 Geometry of the TMT. The axis $\mathrm{Y}$ points towards the viewer from the $\mathrm{XZ}$ plane. 




Figure 12 Global view of neutron fluxes in the TMT as a function of $\mathrm{Z}$ and $\mathrm{X}$ distances Flux is given in units neutrons per $\mathrm{cm}^{2}$ per second per incident proton. 


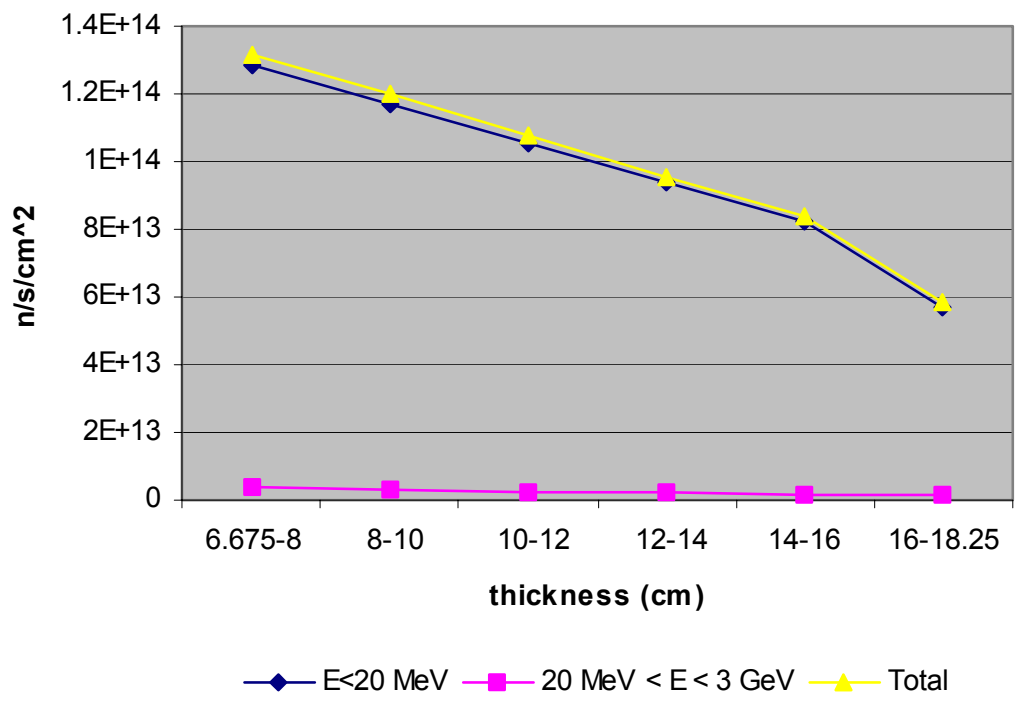

Figure 13 Level of neutron fluxes over a 9-liter volume in the TMT

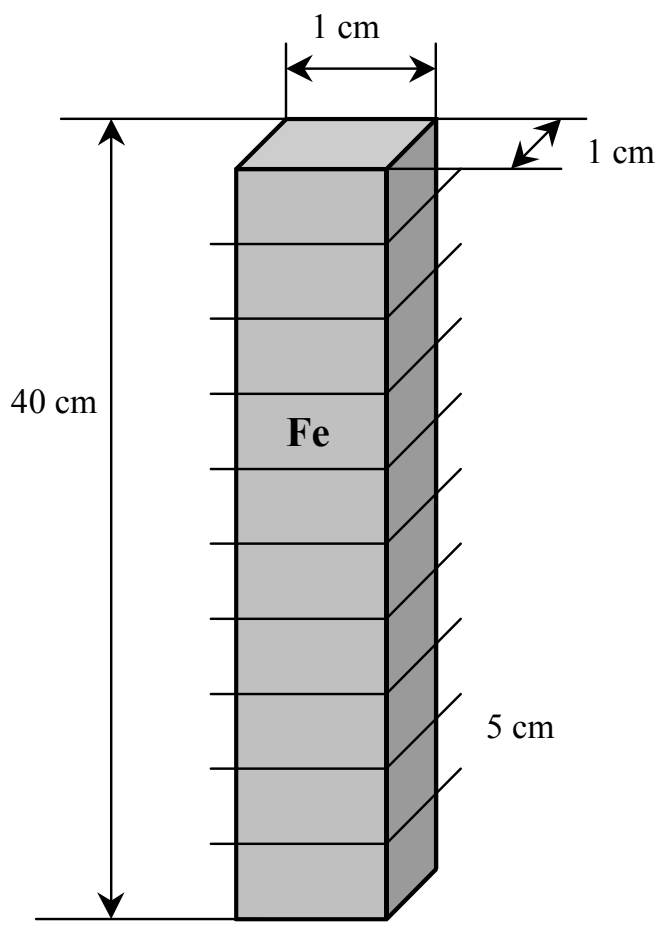

Figure 14 Irradiation sample 


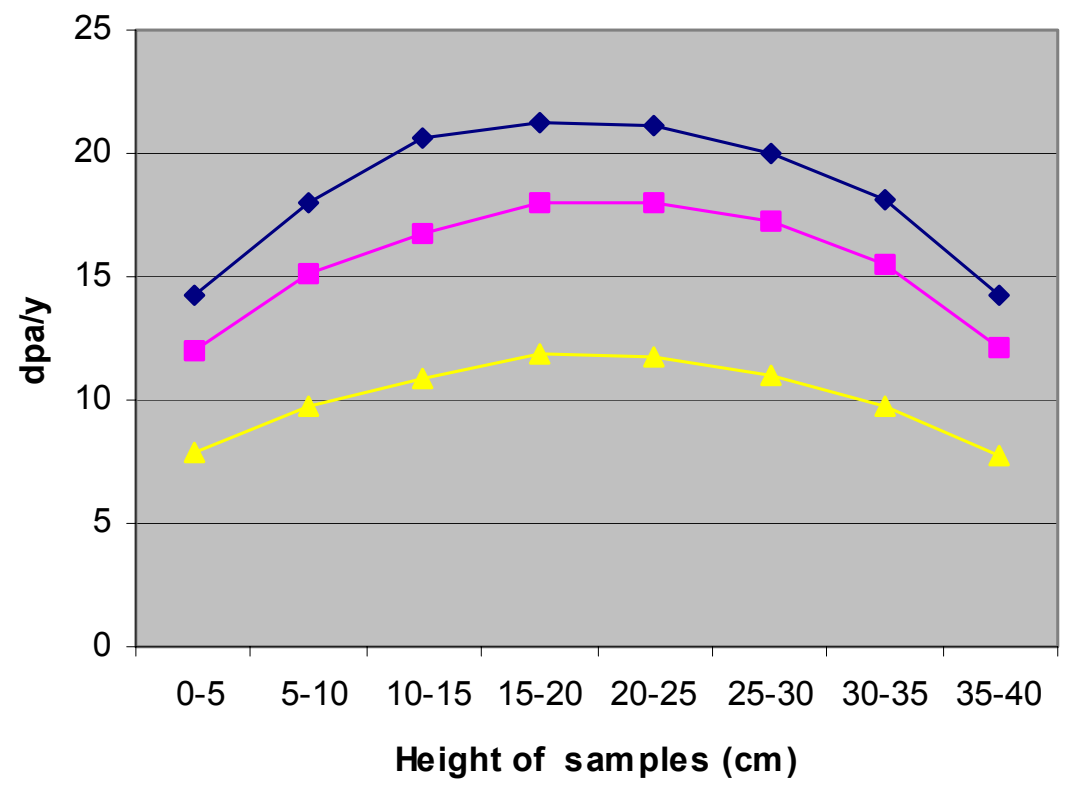

$\multimap$ sample $1 \multimap$ sample $2 \multimap$ sample 3

Figure 15 Neutron induced damage in the irradiation samples (TMT case)

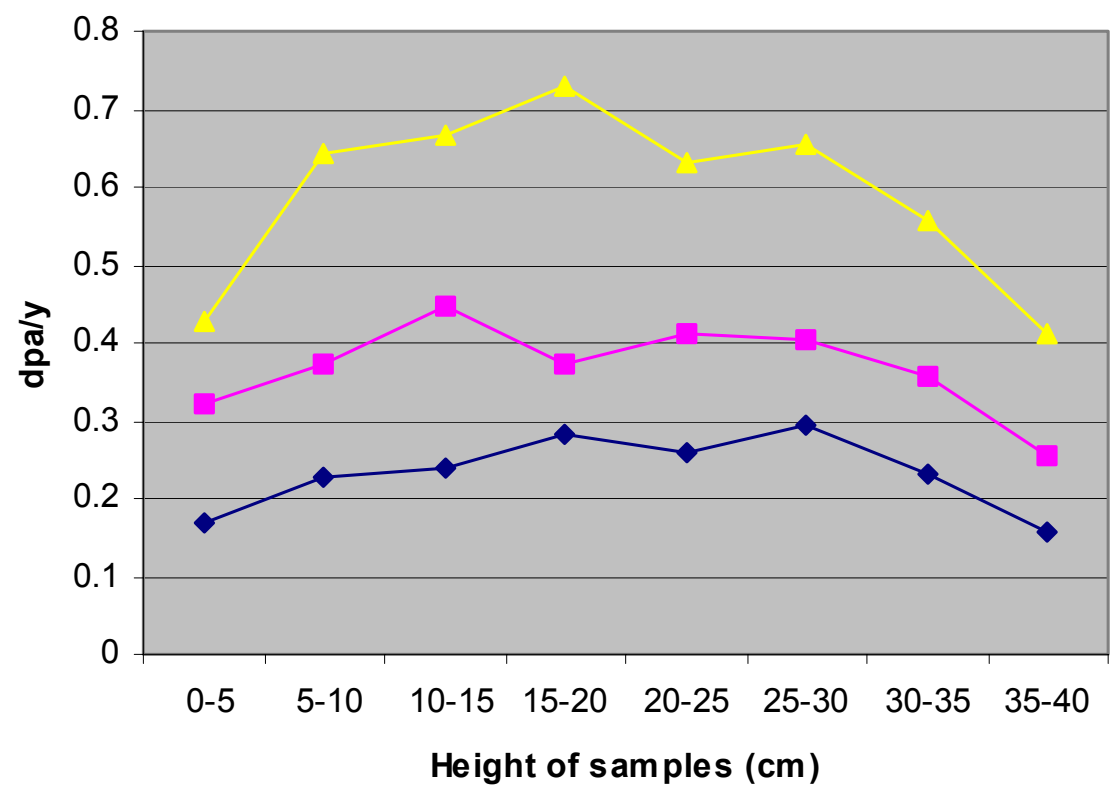

$\multimap$ sample $1 \multimap$ sample $2 \multimap$ sample 3

Figure 16 Proton induced damage in the irradiation samples (TMT case) 
sample 1

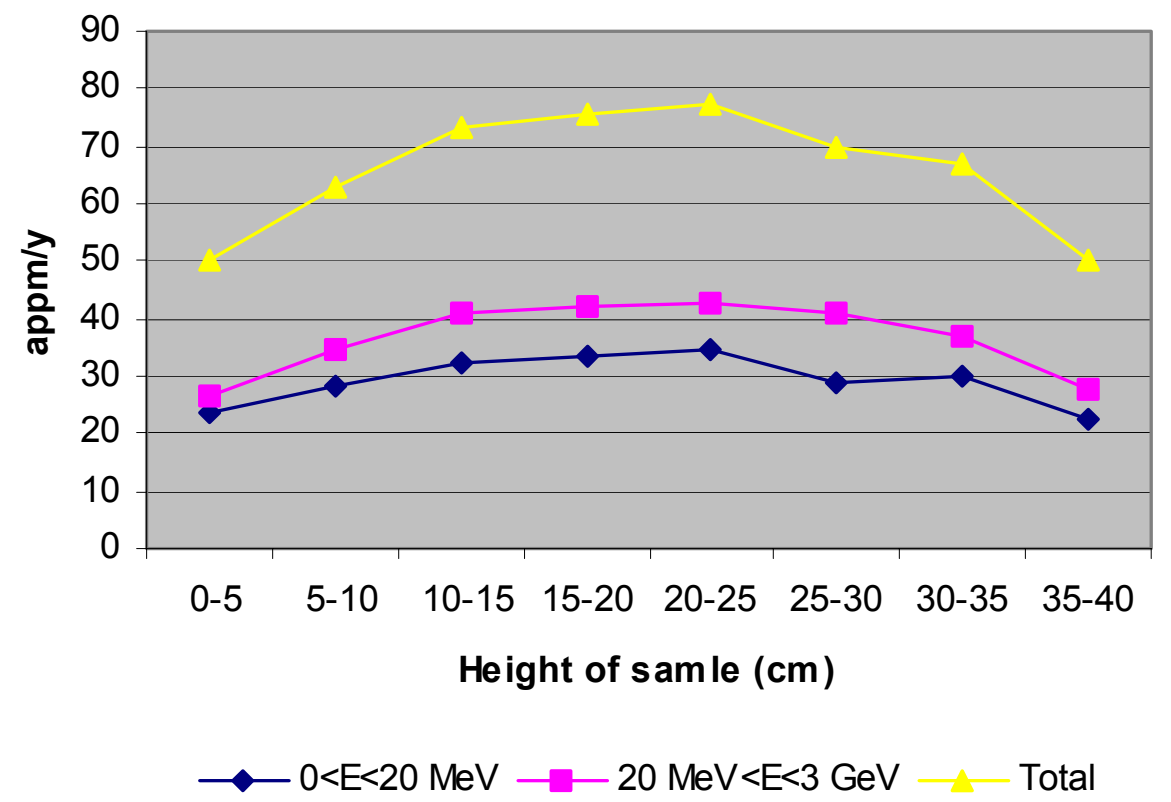

Figure 17 Helium production by low and high-energy neutrons in the sample 1 (TMT case) sample 2

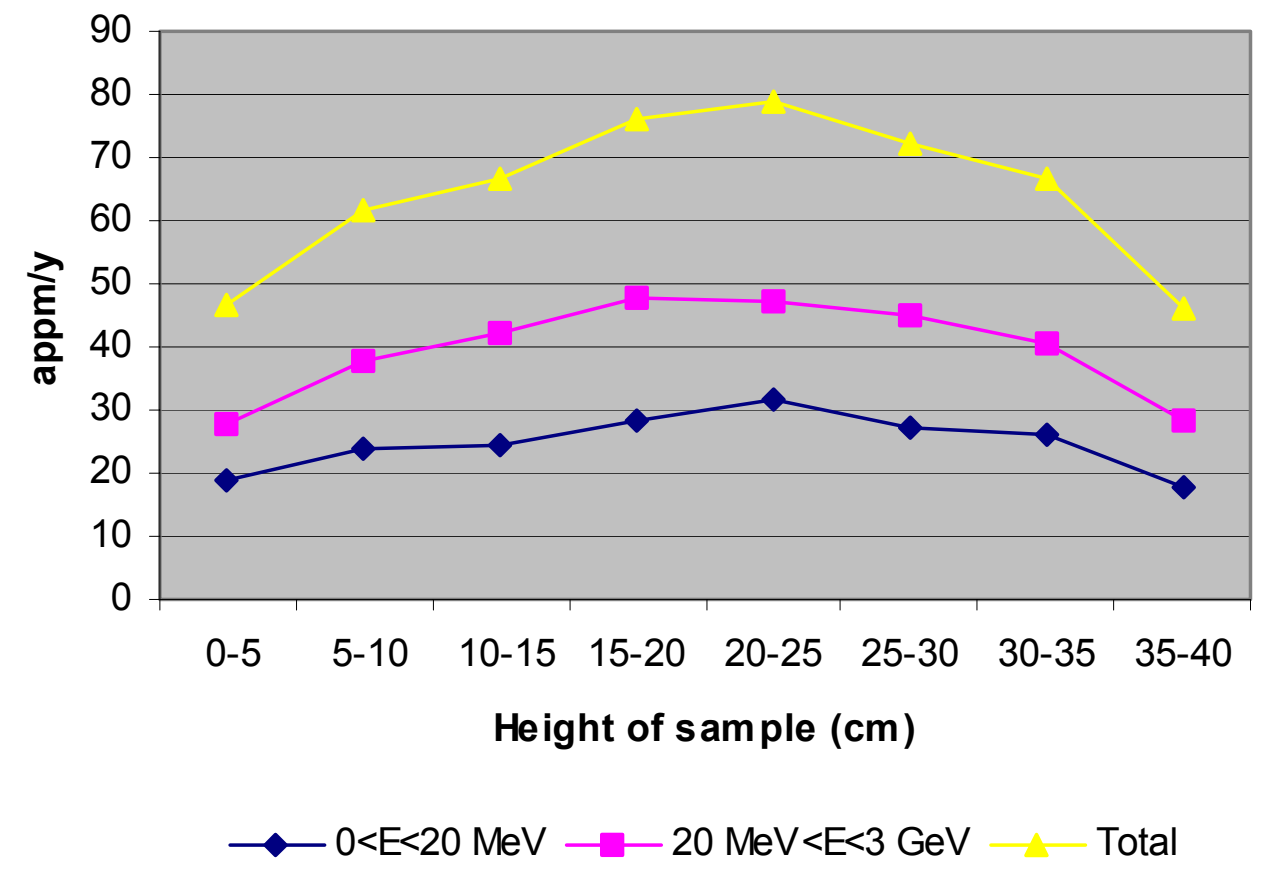

Figure 18 Helium production by low and high-energy neutrons in the sample 2 (TMT case) 
sample 3

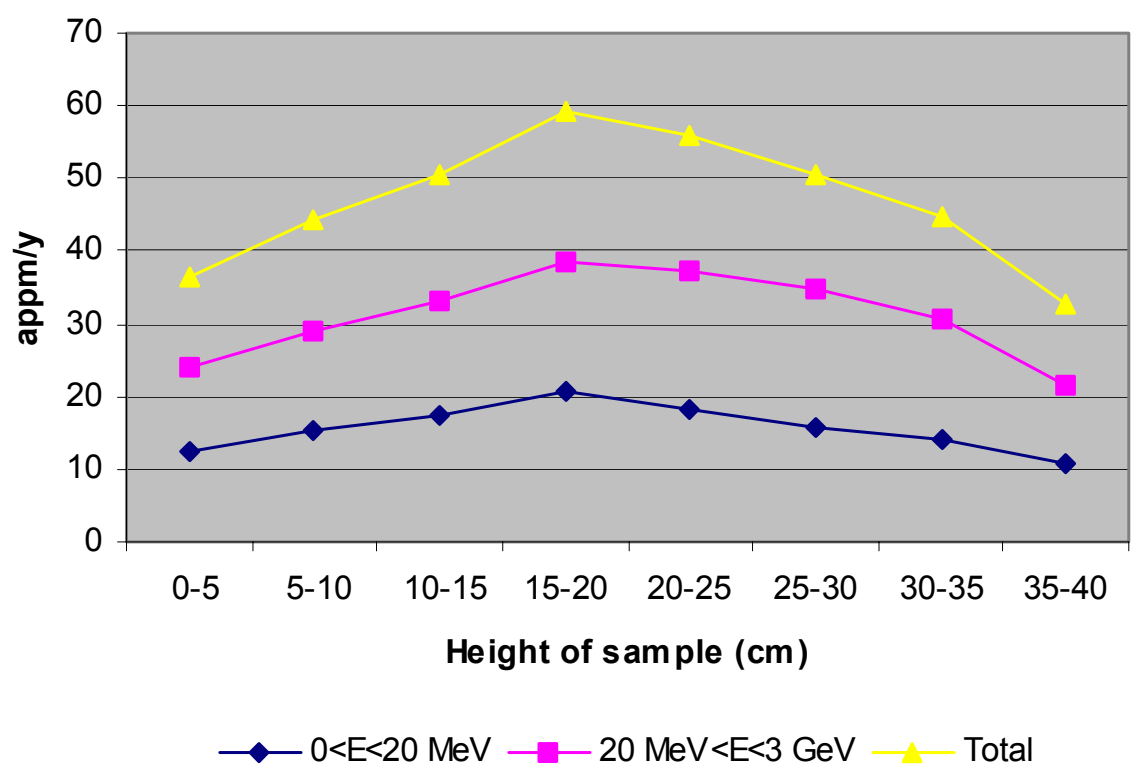

Figure 19 Helium production by low and high-energy neutrons in the sample 3 (TMT case)

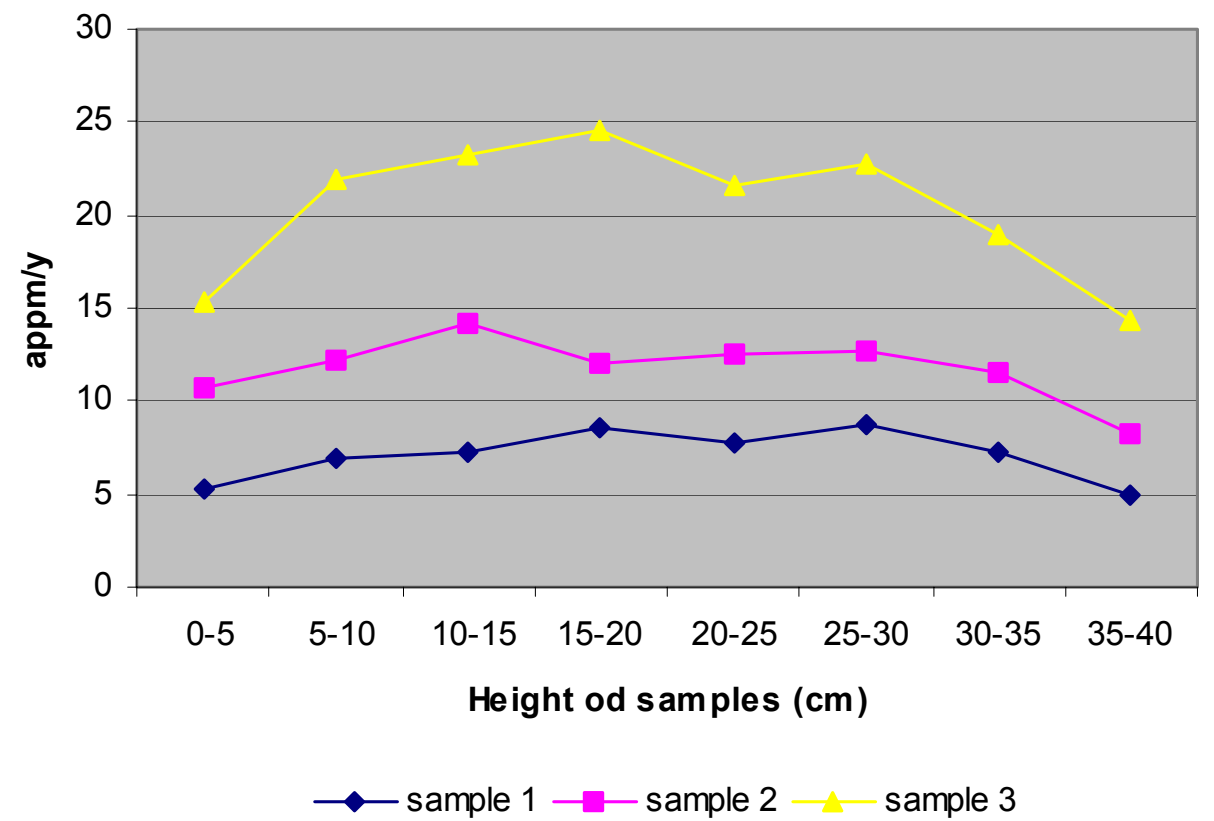

Figure 20 Helium production by protons in the irradiation samples (TMT case) 


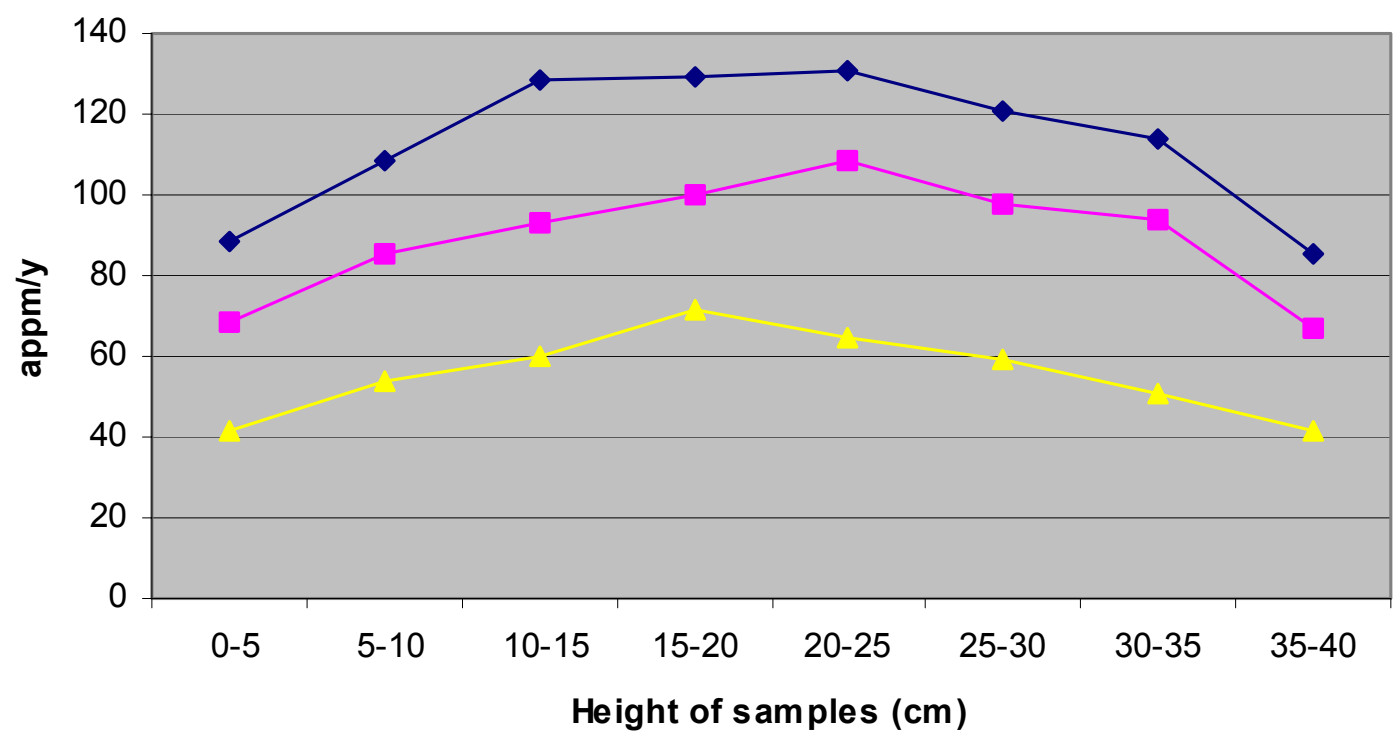

$\sim$ sample $1 \multimap$ sample $2 \multimap$ sample 3

Figure 21 Hydrogen production by neutrons in the irradiation samples (TMT case) 